\title{
Chirality-Directed Regioselectivity: An Approach for the Synthesis of Alternating Poly(Lactic-co-Glycolic Acid)
}

\author{
Yiye Lu, ${ }^{\dagger}$ Jordan H. Swisher, ${ }^{\ddagger}$ Tara Y. Meyer, ${ }^{*} \ddagger$ and Geoffrey W. Coates ${ }^{*}{ }^{\dagger}$ \\ ${ }^{\dagger}$ Department of Chemistry and Chemical Biology, Baker Laboratory, Cornell University, Ithaca, New York \\ 14853-1301, United States \\ ${ }^{*}$ Department of Chemistry, University of Pittsburgh, Pittsburgh, Pennsylvania 15260-8929, United States
}

\section{Table of contents}

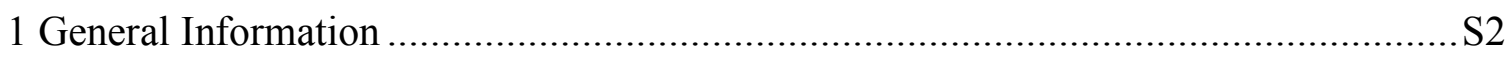

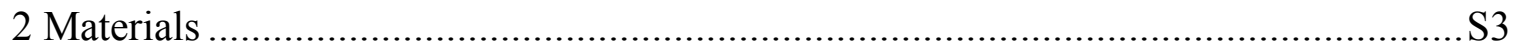

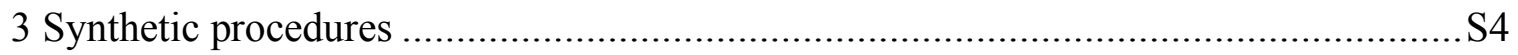

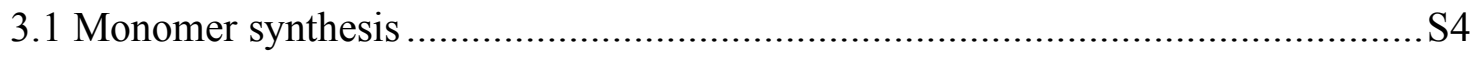

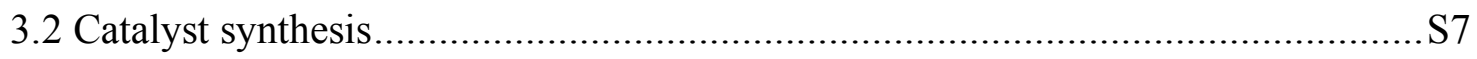

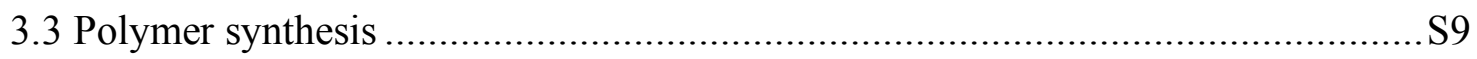

4 Experimental details and polymer characterization .............................................S11

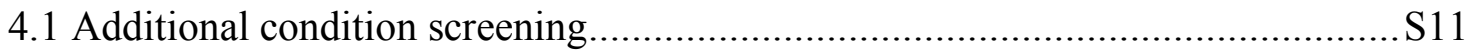

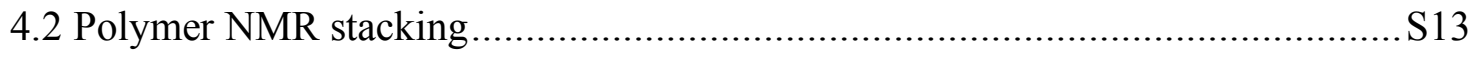

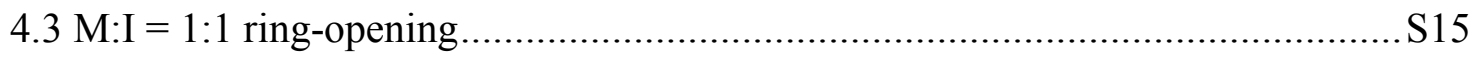

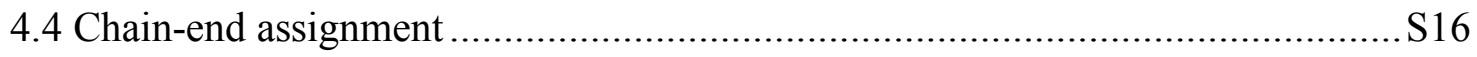

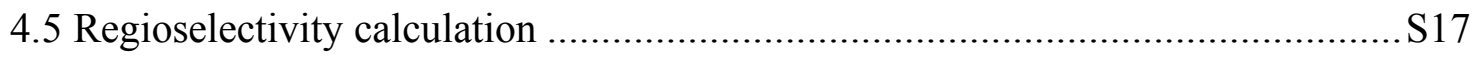

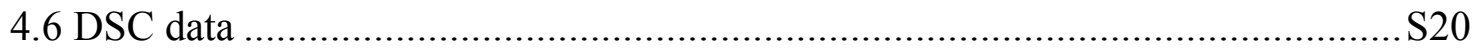

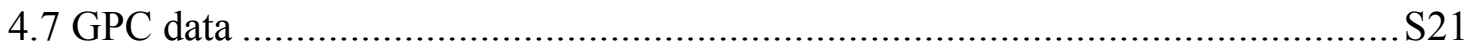

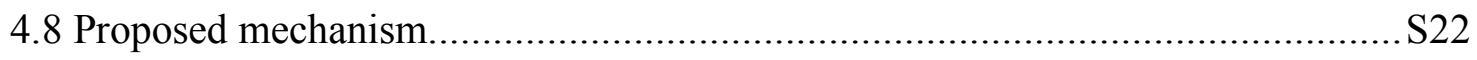

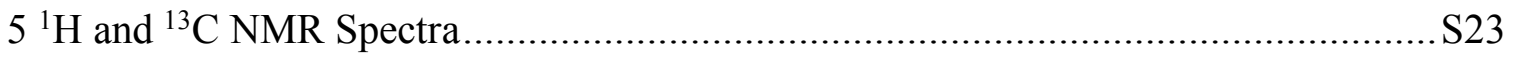

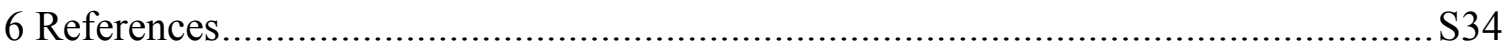




\section{General Information}

All manipulations of air and water sensitive compounds were carried out under nitrogen in an MBraun Labmaster glovebox or by using standard Schlenk line technique. ${ }^{1} \mathrm{H}$ and ${ }^{13} \mathrm{C}$ NMR spectra were recorded on Bruker AVANCE III HD $\left({ }^{1} \mathrm{H}, 400\right)$ spectrometer with a BBF/1H broadband observe probe, Bruker AVANCE III HD $\left({ }^{1} \mathrm{H}, 500 \mathrm{MHz}\right)$ spectrometer with a broadband Prodigy cryoprobe or Varian INOVA $600\left({ }^{1} \mathrm{H}, 600 \mathrm{MHz}\right)$ spectrometer with a Varian $5 \mathrm{~mm}$ inverse, triple-resonance probehead. Two-dimensional NMR experiments were acquired on the Varian INOVA $600\left({ }^{1} \mathrm{H}, 600 \mathrm{MHz}\right)$ spectrometer using standard pulse sequences bsgHSQCAD and bsgHMBC supplied in VnmrJ 3.2. All the NMR experiments were carried out at $25^{\circ} \mathrm{C}$ and processed with MestReNova software 14.1.0. Chemical shifts $(\delta)$ for ${ }^{1} \mathrm{H}$ spectra were referenced to protons on the residual solvent (7.26 ppm for $\mathrm{CDCl}_{3}, 2.08 \mathrm{ppm}$ for $\mathrm{C}_{6} \mathrm{D}_{5} \mathrm{CD}_{3}$ ). Chemical shifts $(\delta)$ for ${ }^{13} \mathrm{C}$ NMR spectra were referenced to deuterated solvent itself ( $77.16 \mathrm{ppm}$ for $\left.\mathrm{CDCl}_{3}\right)$. NMR-spectroscopic data are reported as follows: chemical shift, multiplicity $(\mathrm{s}=\operatorname{singlet}, \mathrm{d}=$ doublet, $\mathrm{t}=$ triplet, $\mathrm{q}=$ quartet, $\mathrm{m}=$ multiplet, $\mathrm{br}=$ broad$)$, integration and coupling constants $(\mathrm{Hz})$. Highresolution mass spectrometry (HRMS) analyses were performed on a Thermo Scientific Exactive Orbitrap MS system equipped with an Ion Sense DART ion source or an electrospray ionization (ESI) source.

Flash column chromatography was performed using silica gel (particle size 40-64 $\mu \mathrm{m}$, 230-400 mesh). Gel permeation chromatography (GPC) analyses were carried out using an Agilent 1260 Infinity GPC System equipped with an Agilent 1260 Infinity autosampler

and a refractive index detector. The Agilent GPC system was equipped with two Agilent 
PolyPore columns (5-micron, $4.6 \mathrm{~mm}$ ID) which were eluted with THF at $30{ }^{\circ} \mathrm{C}$ at 0.3 $\mathrm{mL} / \mathrm{min}$ and calibrated using monodisperse polystyrene standards.

Differential scanning calorimetry (DSC) measurements of polymer samples were performed on a Mettler-Toledo Polymer DSC instrument equipped with a chiller and an autosampler. Samples were prepared in aluminum pans. All polyesters were analyzed using the following heating program: $-70{ }^{\circ} \mathrm{C}$ to $200{ }^{\circ} \mathrm{C}$ at $25{ }^{\circ} \mathrm{C} / \mathrm{min}, 200$ to $-70{ }^{\circ} \mathrm{C}$ at $10{ }^{\circ} \mathrm{C} / \mathrm{min}$, and then $-70{ }^{\circ} \mathrm{C}$ to $200{ }^{\circ} \mathrm{C}$ at $25{ }^{\circ} \mathrm{C} / \mathrm{min}$. Data were processed using StarE software. All reported glass transition temperatures were observed on the second heating cycle.

\section{Materials}

Solvents for air sensitive reactions were purchased from Fisher and sparged with ultrahigh purity (UHP) grade nitrogen and either passed through two columns containing reduced copper (Q-5) and alumina (PhMe and THF) or passed through two columns of alumina (DCM) and dispensed into an oven-dried Straus flask, followed by three freezepump-thaw cycles, and vacuum transferred before use. Deuterated chloroform and deuterated toluene were purchased from Cambridge Isotope Laboratories, dried over calcium hydride for three days, vacuum transferred to an oven-dried Schlenk flask, degassed by three freeze-pump-thaw cycles, and stored under nitrogen. All solvents were stored over $3 \AA$ molecular sieves. $3 \AA$ molecular sieves were purchased from Strem and activated by heating at $200{ }^{\circ} \mathrm{C}$ under vacuum for 18 hours.

Other bench-top solvents (EtOAc, hexanes, $\mathrm{MeOH}, \mathrm{EtOH}, \mathrm{DCM}, \mathrm{MeCN}, \mathrm{CDCl}_{3}$, etc.) were used as received. All other chemicals and reagents were purchased from commercial sources (Aldrich, Oakwood Chemical, Strem, Advanced ChemBlocks Inc., TCI, Alfa 
Aesar, Acros, and Fisher) and used without further purification.

\section{Synthetic procedures}

\subsection{Monomer synthesis}

\section{Scheme S1. Monomer Synthesis}
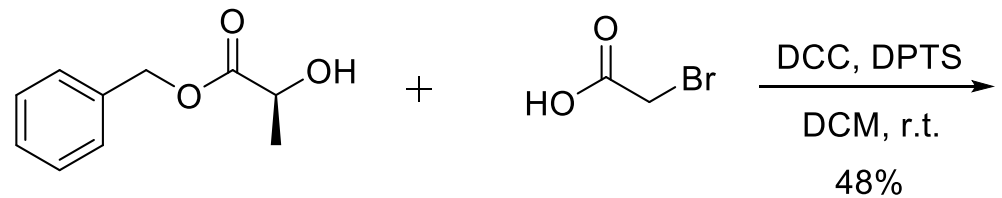<smiles>CC(OC(=O)CBr)C(=O)OCc1ccccc1</smiles>

S1

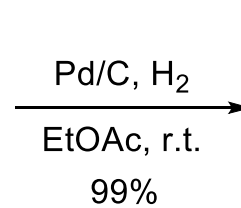

$99 \%$<smiles>CC(OC(=O)CBr)C(=O)O</smiles>

S2

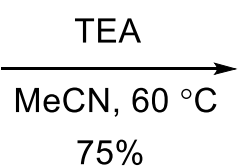

$75 \%$<smiles>C[C@H]1OC(=O)COC1=O</smiles>

S3

(S)-3-methyl glycolide $((S)-\mathrm{MeG})$ was synthesized following Scheme S1, according to modified literature procedures. ${ }^{1-3}$

\section{Benzyl (S)-2-(2-bromoacetoxy)propanoate (S1)}

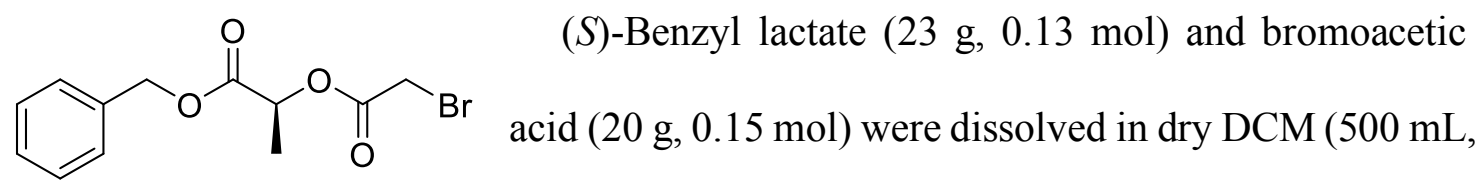
$0.25 \mathrm{M}$ ) in a flame dried Schlenk flask under nitrogen. 4-(Dimethylamino)pyridinium $p$ toluenesulfonate (DPTS) $(5.9 \mathrm{~g}, 0.021 \mathrm{~mol})$ and $N, N^{\prime}$-dicyclohexylcarbodiimide (DCC) (28.5 g, $0.138 \mathrm{~mol})$ were then added to the flask and the solution was allowed to stir overnight. The reaction mixture was then diluted with hexanes and filtered to remove dicyclohexylurea (DCU), and the filtrate was concentrated and purified via column chromatography (silica, EtOAc/hexanes) to yield a colorless oil (18.5 g, 48\% yield). 
${ }^{1}$ H NMR (400 MHz, $\left.\mathbf{C D C l}_{3}\right) \delta 7.35(\mathrm{~m}, 5 \mathrm{H}), 5.20(\mathrm{~m}, 3 \mathrm{H}), 3.90(\mathrm{~s}, 2 \mathrm{H}), 1.54(\mathrm{~d}, J=7.1$ $\mathrm{Hz}, 3 \mathrm{H}) ;{ }^{13} \mathbf{C}$ NMR (100 MHz, $\left.\mathbf{C D C l}_{3}\right) \delta$ 170.0, 166.8, 135.3, 128.8, 128.7, 128.4, 70.3, 67.4, 25.4, 16.9; HRMS (ESI): $\mathrm{m} / z$ calculated for $\mathrm{C}_{12} \mathrm{H}_{14} \mathrm{BrO}_{4}[\mathrm{M}+\mathrm{H}]^{+} 301.00755$, found 301.00745 .

\section{(S)-2-(2-Bromoacetoxy)propanoic acid (S2)}

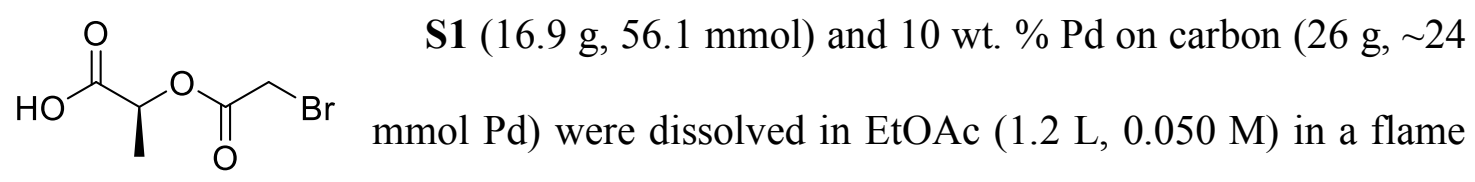
dried Schlenk flask under nitrogen. The flask was purged with $\mathrm{H}_{2}$ twice, and then allowed to stir for $10 \mathrm{~min}$ at r.t. under $1 \mathrm{~atm} \mathrm{H}_{2}$. The reaction was monitored closely by TLC. Upon completion, the reaction mixture was filtered to recover catalyst, and filtered again over celite and concentrated in vacuo to yield an orange oil (11.6 g, 99\% yield). Recovered catalyst could be dried and reused with similar activity several times.

${ }^{1} \mathrm{H}$ NMR (400 MHz, CDCl $) \delta 10.53(\mathrm{~s}, 1 \mathrm{H}), 5.19(\mathrm{q}, J=7.1 \mathrm{~Hz}, 1 \mathrm{H}), 3.92(\mathrm{~s}, 2 \mathrm{H}), 1.59$ $(\mathrm{d}, J=7.2 \mathrm{~Hz}, 3 \mathrm{H}) ;{ }^{13} \mathbf{C}$ NMR (100 MHz, $\left.\mathbf{C D C l}_{3}\right) \delta 175.7,166.8,69.7,25.2,16.8$; HRMS (ESI): $m / z$ calculated for $\mathrm{C}_{5} \mathrm{H}_{8} \mathrm{BrO}_{4}[\mathrm{M}+\mathrm{H}]^{+} 210.96060$, found 210.94322 .

\section{(S)-3-Methyl-1,4-dioxane-2,5-dione (S3)}

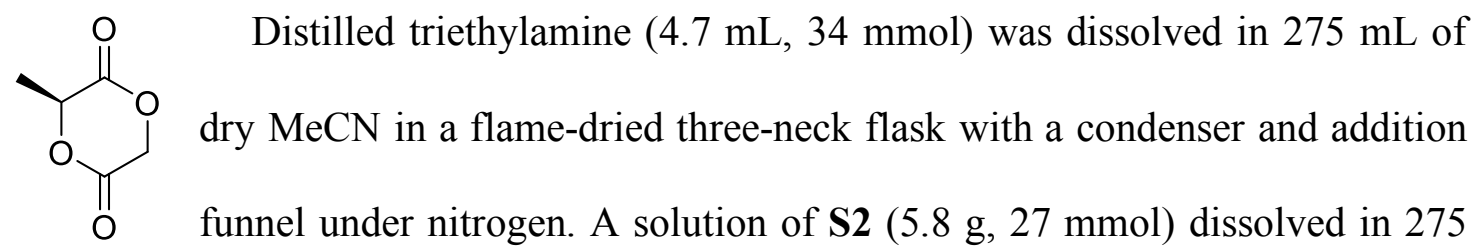
$\mathrm{mL}(550 \mathrm{~mL}$ total, $0.050 \mathrm{M}$ ) of dry $\mathrm{MeCN}$ was added dropwise through the addition funnel at $60{ }^{\circ} \mathrm{C}$ for $20 \mathrm{~min}$. The reaction mixture was allowed to stir at $60{ }^{\circ} \mathrm{C}$ for an additional 10 min and was then quenched by adding $3 \mathrm{~mL}$ of $\mathrm{AcOH}$. The reaction mixture was 
concentrated and purified via column chromatography (silica, EtOAc/hexanes) to yield a white solid (2.67 g, 75\% yield).

${ }^{1} \mathbf{H}$ NMR (500 MHz, CDCl $) \delta 5.03(\mathrm{q}, J=6.8 \mathrm{~Hz}, 1 \mathrm{H}), 4.96(\mathrm{~d}, J=16.5 \mathrm{~Hz}, 1 \mathrm{H}), 4.91$ $(\mathrm{d}, J=16.5 \mathrm{~Hz}, 1 \mathrm{H}), 1.70(\mathrm{~d}, J=6.8 \mathrm{~Hz}, 3 \mathrm{H}) ;{ }^{13} \mathbf{C} \mathbf{N M R}\left(\mathbf{1 2 5} \mathbf{M H z}, \mathbf{C D C l}_{3}\right) \delta 166.4(\mathrm{~d}, J$ $=1.3 \mathrm{~Hz}), 164.6(\mathrm{~d}, J=1.4 \mathrm{~Hz}), 72.2,65.7,16.5 ;$ HRMS $\left(\right.$ ESI): $\mathrm{m} / z$ calculated for $\mathrm{C}_{5} \mathrm{H}_{7} \mathrm{O}_{4}$ $[\mathrm{M}+\mathrm{H}]^{+}$131.03443, found 131.03381.

Spectral data matched those reported in the literature. ${ }^{3}$

The product from column chromatography was heated to melt as a clear liquid and dried overnight under vacuum. When cooled down, it formed back to a chunk of white solid. It was then chopped down to small pieces and sublimed twice under vacuum at $40{ }^{\circ} \mathrm{C}$. The sublimed solids were collected and stored under nitrogen. For the small-scale sublimation (suitable for $50-1000 \mathrm{mg}$ ), crude product was placed in a $20 \mathrm{~mL}$ scintillation vial, equipped with a rubber septum and a needle. The combined vial was placed in a drying tube, heated under vacuum, until most solids got collected at the inner side of the rubber septum, with yellow liquid left at the bottom of the vial. The sublimed solids were scraped off and collected in a vial in glovebox. The monomer was now ready to use for polymerization. 


\subsection{Catalyst synthesis}

$(R)$-(SalBinam)AlO ${ }^{i}$ Pr was synthesized according to a previous literature from our group with slight modification (Scheme S2). ${ }^{4}$

\section{Scheme S2. Catalyst Synthesis}
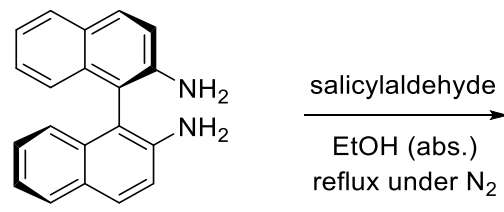

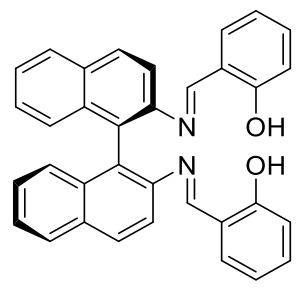

(R)-S4

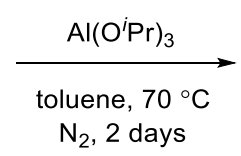

$(R)-\mathrm{S} 5$

$(R)-N, N^{\prime}$-Bis(salicylidene)-1,1'-binaphthyl-2,2'-diamine ((R)-SalBinam) $((R)-S 4)$<smiles>Oc1ccccc1/C=N/c1ccc2ccccc2c1/C(=N\c1cccc2ccccc12)c1c(O)ccc2ccccc12</smiles>

To a round bottom flask, $(R)$-binaphthyl diamine (BINAM) (102 mg, $0.360 \mathrm{mmol}, 1.00$ eq.), salicylaldehyde ( $76.7 \mu \mathrm{L}, 0.720$ mmol, 2.00 eq.) and EtOH (abs.) $(3.0 \mathrm{~mL}, 0.12 \mathrm{M})$ were added.

The reaction was heated to reflux overnight under $\mathrm{N}_{2}$. The mixture turned yellow and formed into a suspension. After reaction, the resulting solid was filtered, wash with cold EtOH, and dried under vacuum overnight, yielding a yellow solid as $(R)$-SalBinam (quant. yield).

${ }^{1} \mathbf{H}$ NMR (500 MHz, $\left.\mathbf{C D C l}_{3}\right) \delta 12.10(\mathrm{~s}, 2 \mathrm{H}), 8.69(\mathrm{~s}, 1 \mathrm{H}), 8.12(\mathrm{~d}, J=8.8 \mathrm{~Hz}, 1 \mathrm{H}), 7.98$ (d, $J=8.2 \mathrm{~Hz}, 2 \mathrm{H}), 7.66$ (d, $J=8.8 \mathrm{~Hz}, 2 \mathrm{H}), 7.46$ (t, $J=7.4 \mathrm{~Hz}, 2 \mathrm{H}), 7.29$ (t, $J=7.6 \mathrm{~Hz}$, 2H), $7.25-7.17(\mathrm{~m}, 6 \mathrm{H}), 6.78(\mathrm{t}, J=7.5 \mathrm{~Hz}, 2 \mathrm{H}), 6.74(\mathrm{~d}, J=8.3 \mathrm{~Hz}, 2 \mathrm{H}) ;{ }^{13} \mathbf{C}$ NMR (125 $\left.\mathbf{M H z}, \mathbf{C D C l}_{3}\right) \delta 162.0,160.9,143.8,133.3,132.95,132.7,132.3,130.2,129.7,128.5$, 127.2, 126.6, 126.1, 119.4, 118.8, 117.2, 117.0; HRMS (DART-MS): $\mathrm{m} / \mathrm{z}$ calculated for $\mathrm{C}_{34} \mathrm{H}_{25} \mathrm{~N}_{2} \mathrm{O}_{2}[\mathrm{M}+\mathrm{H}]^{+}$493.1916, found 493.1912. 
Spectral data matched those reported in the literature. ${ }^{5}$

\section{Complex (R)-(SalBinam)AlO ${ }^{i} \operatorname{Pr}((R)-S 5)$}

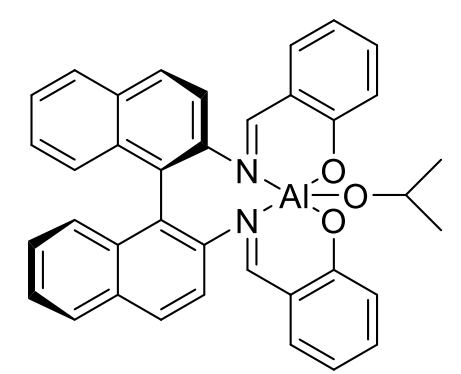

$\mathrm{Al}\left(\mathrm{O}^{i} \mathrm{Pr}\right)_{3} \quad 99.99+\%$ was purchased from Aldrich and stored under nitrogen as received. In a glovebox, excess $\mathrm{Al}\left(\mathrm{O}^{i} \mathrm{Pr}\right)_{3}(100 \mathrm{mg})$ was weighed in a $4 \mathrm{~mL}$ vial and sealed with a Teflon-lined cap. It was brought out of the box, heated with heat gun to a liquid and maintained for $1 \mathrm{~min}$. After cooling to room temperature, the heating was repeated for another 4 times, until there was almost no solid left. The heating is to transfer the $\mathrm{Al}\left(\mathrm{O}^{i} \mathrm{Pr}\right)_{3}$ from an inactive tetramer (solid) into an active trimer (liquid). ${ }^{6}$

The freshly heated $\mathrm{Al}\left(\mathrm{O}^{i} \mathrm{Pr}\right)_{3}$ was brought back to the glovebox. Another $4 \mathrm{~mL}$ vial was loaded with freshly heated $\mathrm{Al}\left(\mathrm{O}^{i} \mathrm{Pr}\right)_{3}(30.6 \mathrm{mg}, 0.150 \mathrm{mmol}, 1.00$ eq. $),(R)$-SalBinam $(73.8$ $\mathrm{mg}, 0.150 \mathrm{mmol}, 1.00$ eq. $)$, and toluene $(2.5 \mathrm{~mL}, 0.060 \mathrm{M})$. The vial was capped with a Teflon-lined cap, taken out of the box, taped with parafilm and electrical tape, and heated to $70{ }^{\circ} \mathrm{C}$ for 2 days. After reaction, the vial was brought back to glovebox and placed in a drying tube with rubber septum and needle. Solvent was removed in vacuo, yielding a bright yellow solid (quant. yield).

(S)-(SalBinam)AlO ${ }^{i} \operatorname{Pr}$ and $r a c-($ SalBinam $) \mathrm{AlO}^{i} \operatorname{Pr}$ were synthesized following a similar procedure using the appropriate $S$ or $r a c$ isomer of the BINAM starting material.

HRMS (DART-MS): $m / z$ calculated for $\mathrm{C}_{34} \mathrm{H}_{22} \mathrm{AlN}_{2} \mathrm{O}_{2}\left[\mathrm{M}-\mathrm{C}_{3} \mathrm{H}_{7} \mathrm{O}\right]^{+}$517.1497, found 517.1492. 


\subsection{Polymer synthesis}

\section{Scheme S3. Polymer Synthesis}

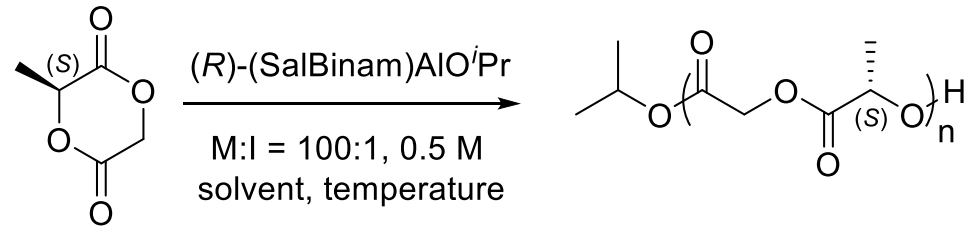

S3

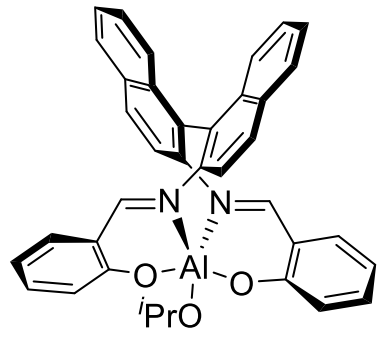

(R)-(SalBinam)AIO'Pr

(R)-S5

General Procedure for small scale synthesis: In a glovebox, $(S)$-3-methyl glycolide (26.0 mg, $0.200 \mathrm{mmol}, 100$ eq.) was added to an oven-dried $4 \mathrm{~mL}$ vial equipped with a Teflon-coated stir bar. Catalyst solution was freshly made at a concentration of $2.88 \mathrm{mg} / \mathrm{mL}$ in dry toluene. $0.4 \mathrm{~mL}$ of the catalyst solution, containing $(R)-($ SalBinam $) \mathrm{AlO}^{i} \operatorname{Pr}(1.15 \mathrm{mg}$, $2.00 \mu \mathrm{mol}, 1.00$ eq.) and toluene $(0.4 \mathrm{~mL}, 0.5 \mathrm{M})$, was added to the above vial. The vial was capped with a Teflon-lined cap, brought out of the box, taped with parafilm and electrical tape, gently heated with heat gun to ensure monomer dissolution if toluene was used as solvent. It was then heated under stirring at the desired temperature for the certain amount of time. After reaction, the mixture was quenched with one drop of glacial $\mathrm{AcOH}$, and then diluted and transferred with DCM into a round bottom flask. Solvent was removed in vacuo, and the product was re-dissolved with $\mathrm{CDCl}_{3}$ for $\mathrm{NMR}$. An aliquot was taken, dried and re-dissolved with HPLC-grade THF for GPC. The crude polymer was precipitated with $\mathrm{CDCl}_{3}$ and $\mathrm{EtOH}$ twice to yield a white solid.

General Procedure for large scale synthesis: In a glovebox, $(S)-3$-methyl glycolide (291.4 mg, 2.240 mmol, 40.00 eq.), (R)-(SalBinam)AlO ${ }^{i} \operatorname{Pr}(32.3$ mg, $56.0 \mu \mathrm{mol}, 1.00$ eq. ) and toluene $(4.5 \mathrm{~mL}, 0.50 \mathrm{M})$ were added to a flame-dried Schlenk tube equipped with a 
Teflon-coated stir bar. The Schlenk tube was sealed with a greased glass stopper and a clamp. It was brought out of the box, gently heated with heat gun to ensure monomer dissolution if toluene was used as solvent. It was then heated under stirring at the desired temperature for the certain amount of time. After reaction, the mixture was quenched with $0.5 \mathrm{~mL}$ of glacial $\mathrm{AcOH}$, and then diluted and transferred with DCM into a round bottom flask. Solvent was removed in vacuo and re-dissolved with DCM. An aliquot was taken for NMR and GPC. The crude polymer was precipitated with DCM and EtOH twice to yield a white solid.

${ }^{1} \mathbf{H}$ NMR (600 MHz, CDCl $) \delta 5.25(\mathrm{q}, J=7.1 \mathrm{~Hz}, 1 \mathrm{H}), 4.88(\mathrm{~d}, J=16.0 \mathrm{~Hz}, 1 \mathrm{H}), 4.65$ $(\mathrm{d}, J=16.1 \mathrm{~Hz}, 1 \mathrm{H}), 1.59(\mathrm{~d}, J=7.1 \mathrm{~Hz}, 3 \mathrm{H}) ;{ }^{13} \mathbf{C} \mathbf{N M R}\left(\mathbf{1 2 5} \mathbf{M H z}, \mathbf{C D C l}_{3}\right) \delta 169.5,166.6$, $69.3,61.0,16.9$. 


\title{
4 Experimental details and polymer characterization
}

\author{
4.1 Additional condition screening
}

Table S1. Additional Condition Screening ${ }^{a}$

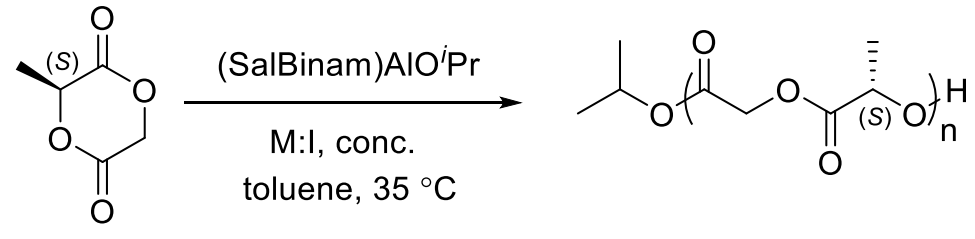

S3

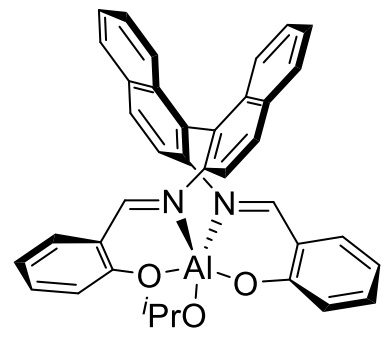

(R)-(SalBinam)AIO'Pr

$(R)-\mathbf{S 5}$

\begin{tabular}{|c|c|c|c|c|c|c|c|c|c|}
\hline entry & initiator & M:I & $\begin{array}{l}\text { conc. } \\
\left(\mathrm{mol} \cdot \mathrm{L}^{-1}\right)\end{array}$ & $\begin{array}{l}\text { time } \\
\text { (h) }\end{array}$ & $\begin{array}{l}\text { conv. } \\
(\%)^{b}\end{array}$ & $\begin{array}{l}M_{\mathrm{n}} \text { theo } \\
(\mathrm{kDa})\end{array}$ & $\begin{array}{l}M_{\mathrm{n} \mathrm{GPC}} \\
(\mathrm{kDa})^{c}\end{array}$ & $\begin{array}{c}D \\
\left(M_{\mathrm{w}} / M_{\mathrm{n}}\right)^{c}\end{array}$ & $\begin{array}{c}\text { regioselectivity } \\
(\%)^{d}\end{array}$ \\
\hline 1 & $(R)-\mathbf{S 5}$ & $40: 1$ & 0.25 & 18 & 94 & 4.8 & 7.6 & 1.22 & 97 \\
\hline 2 & $(R)-\mathbf{S 5}$ & $40: 1$ & 0.5 & 17 & 98 & 5.1 & 7.1 & 1.18 & 96 \\
\hline 3 & $(R)-\mathbf{S 5}$ & $40: 1$ & 1.0 & 18 & 99 & 5.2 & 9.0 & 1.12 & 96 \\
\hline 4 & $(R)-\mathbf{S 5}$ & $40: 1$ & 2.0 & 1.5 & 97 & 4.4 & 7.8 & 1.08 & 97 \\
\hline $5^{e}$ & $(R)-\mathbf{S 5}$ & 100:1 & 0.5 & 21 & 72 & 9.4 & 11.8 & 1.17 & 97 \\
\hline 6 & $(R)-\mathbf{S 5}$ & $100: 1$ & 0.5 & 21 & 72 & 9.4 & 13.0 & 1.13 & 97 \\
\hline 7 & $(R)-\mathbf{S 5}$ & $80: 1$ & 0.5 & 23 & 87 & 9.0 & 11.9 & 1.19 & 97 \\
\hline 8 & $(R)-\mathbf{S 5}$ & $60: 1$ & 0.5 & 16 & 94 & 7.4 & 9.7 & 1.17 & 96 \\
\hline 9 & $(R)-\mathbf{S 5}$ & $10: 1$ & 0.5 & 12 & $>99$ & 1.3 & 2.0 & 1.29 & 90 \\
\hline 10 & $(R)-\mathbf{S 5}$ & $5: 1$ & 0.5 & 16 & $>99$ & 0.7 & n.d. ${ }^{f}$ & n.d. ${ }^{f}$ & 85 \\
\hline 11 & $(R)-\mathbf{S 5}$ & $100: 1$ & 2.0 & 40 & 77 & 10.0 & 11.6 & 1.30 & 96 \\
\hline 12 & $r a c-\mathbf{S 5}$ & 100:1 & 0.5 & 40 & $>99$ & 13.0 & 12.6 & 1.20 & 89 \\
\hline 13 & $(S)-\mathbf{S 5}$ & $100: 1$ & 0.5 & 40 & $>99$ & 13.0 & 13.8 & 1.27 & 84 \\
\hline 14 & $(S)-\mathbf{S 5}$ & 100:1 & 0.5 & 23 & 82 & 10.7 & 13.8 & 1.14 & 85 \\
\hline $15^{g}$ & $(R)-\mathbf{S 5}$ & 100:1 & 0.5 & 21 & 94 & 12.2 & 18.9 & 1.06 & 97 \\
\hline
\end{tabular}

${ }^{a}$ Reaction conditions: all reactions were carried out in toluene at $35{ }^{\circ} \mathrm{C} .{ }^{b}$ Determined by ${ }^{1} \mathrm{H}$ NMR analysis of the crude reaction mixture on reacted and unreacted methine peaks. ${ }^{c}$ Determined by GPC in THF, calibrated with polystyrene standards. ${ }^{d}$ Calculated from the integration of regioerror $\mathrm{CH}_{2}$ peaks and the whole $\mathrm{CH}_{2}$ region in the ${ }^{1} \mathrm{H}$ NMR spectrum. ${ }^{e}$ The solution was not heated with heat gun at the start of the reaction. ${ }^{f}$ Below GPC detection limit. ${ }^{g} \mathrm{DCE}$ as solvent. 
The monomer concentration did not have a significant effect on regioselectivity (Table $\mathrm{S} 1$, entries 1-4). The polymer dispersity was still narrow at a short reaction time in toluene, indicating that transesterification only started to dominate near full conversion (Table S1, entry 4). Without preheating with heat gun to dissolve all the monomer, the dispersity became a bit higher (Table S1, entries 5 and 6). A wide range of M:I can be achieved under the standard condition (Table S1, entries 2, 6-10). When toluene and $(R)$-S5 catalyst were used, it was difficult to reach full conversion even at prolonged reaction time and a higher monomer concentration at $35^{\circ} \mathrm{C}$ (Table S1, entry 11). However, with $(S)$-S5 or rac-S5 catalyst under the same condition, it was able to reach a full conversion (Table S1, entries 12 and 13). It could be inferred that, at the beginning stage, the driving force is the ring opening at the less hindered site under steric control. With the increase in polymer chain length, the polymer became sluggish to move around and react any more in toluene due to the poor solubility. However, when $(S)$-S5 was present, kinetics facilitated the ring-opening to further improve conversion. The favored coordination between $(S)$-S5 and $(S)$-LA carbonyl helped to ring-open at the $(S)$-LA site, and thus it was able to reach a full conversion and a lower regioselectivity. Prolonged reaction time also caused transesterification and slight drop in regioselectivity (Table S1, entries 13 and 14).

Calculation of $M_{\mathrm{n} \text { theo: }}$

$$
\begin{gathered}
M_{n \text { theo }}=\text { conv. } \times \frac{M}{I} \times M W_{M e G} \\
M W_{M e G}=130.099 \mathrm{~g} / \mathrm{mol}
\end{gathered}
$$




\subsection{Polymer NMR stacking}

Table 1, entry 11
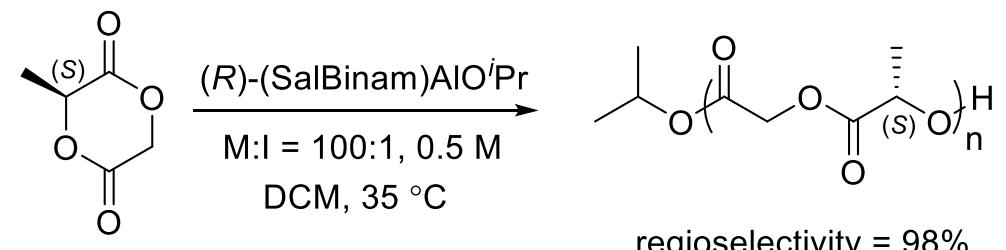

regioselectivity $=98 \%$

\section{Table S1, entry 14}

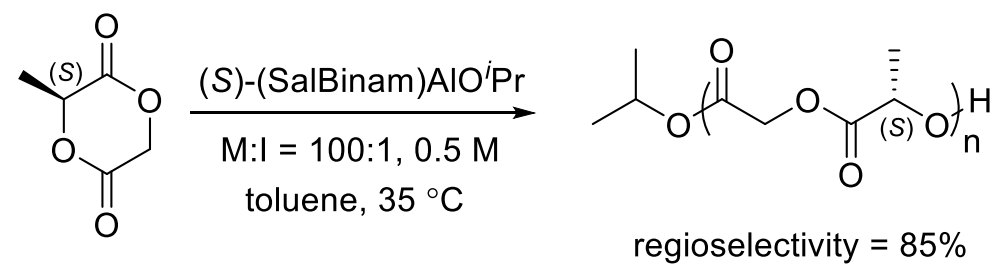

Definition of regioselectivity:

Regioselectivity is the ring-opening probability at the preferred site (B) over the sum of ring-opening probabilities at both possible sites (A and B).

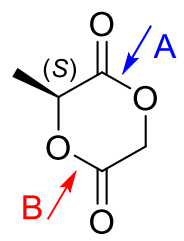

$$
\text { regioselectivity }=\frac{P(B)}{P(A)+P(B)} \times 100 \%
$$




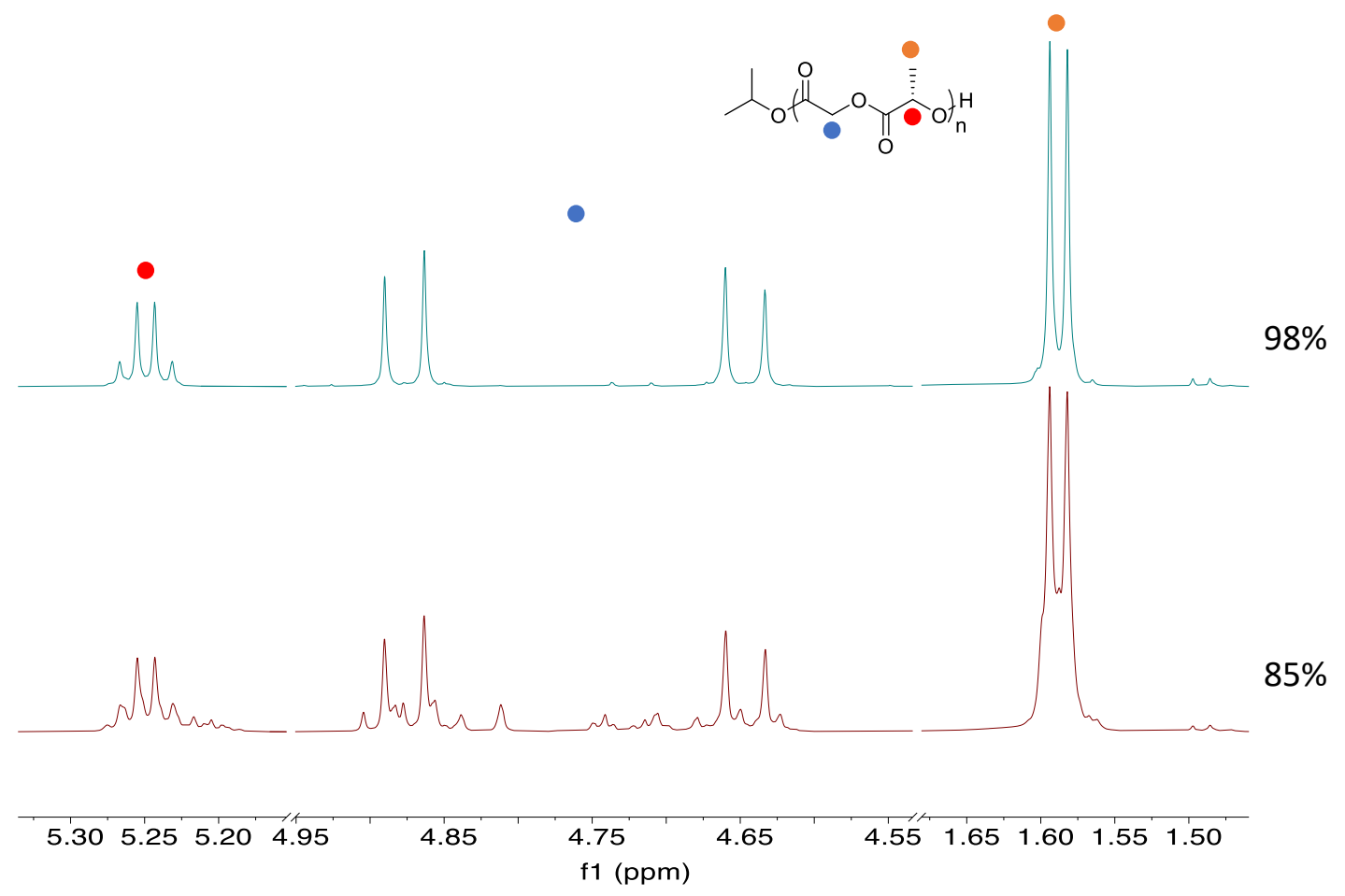

Figure S1. ${ }^{1} \mathrm{H}$ NMR spectra of polymers with high (98\%) and low (85\%) regioselectivities.

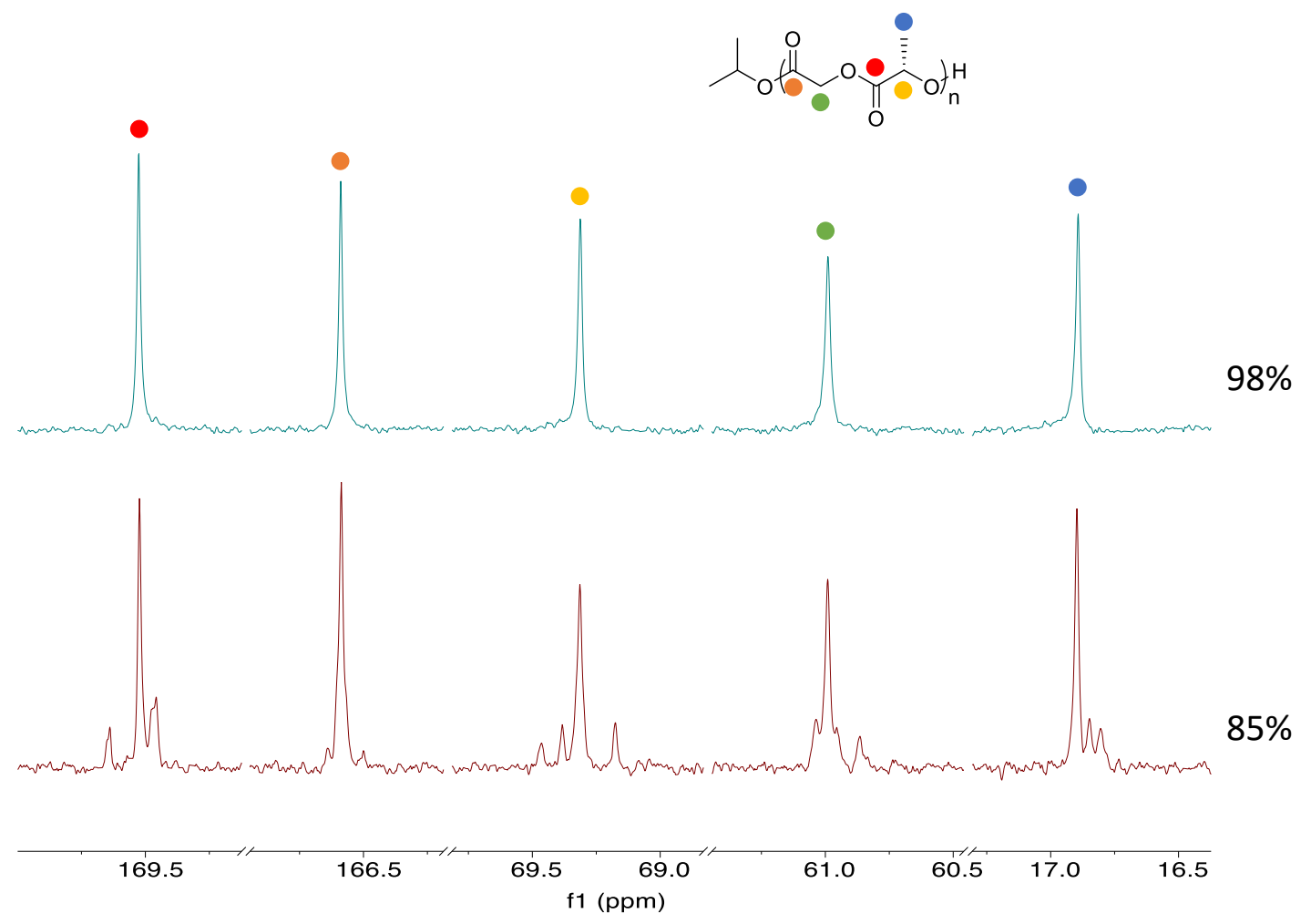

Figure S2. ${ }^{13} \mathrm{C}$ NMR spectra of polymers with high (98\%) and low (85\%) regioselectivities. 
4.3 M:I = 1:1 ring-opening

a)
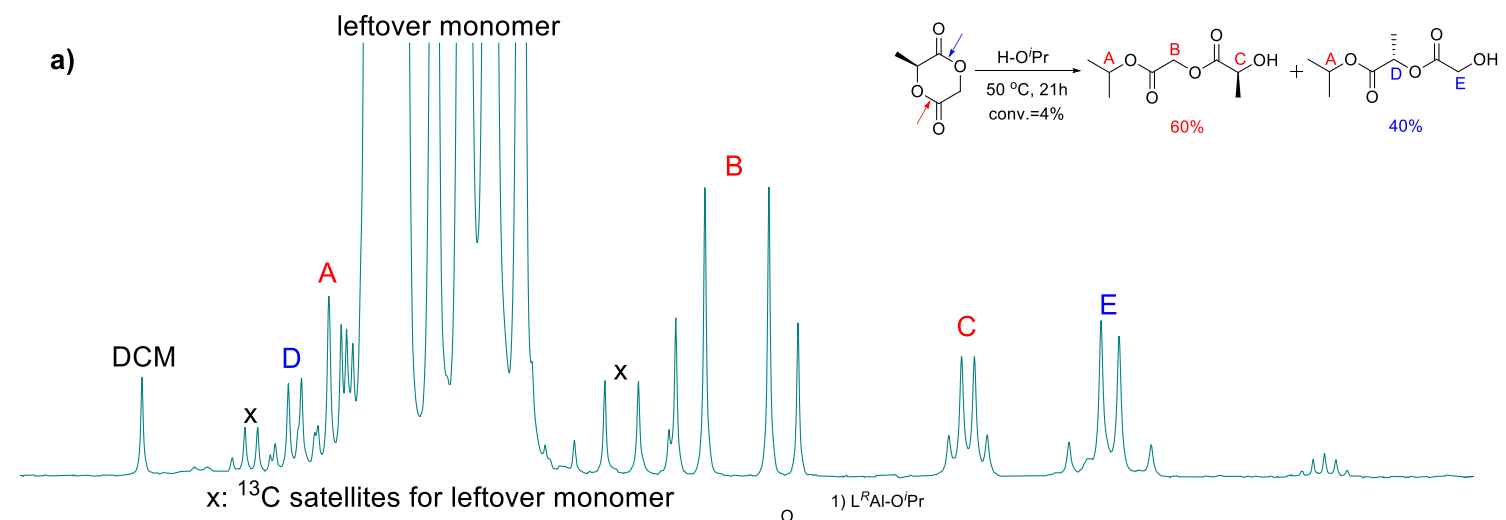

b)
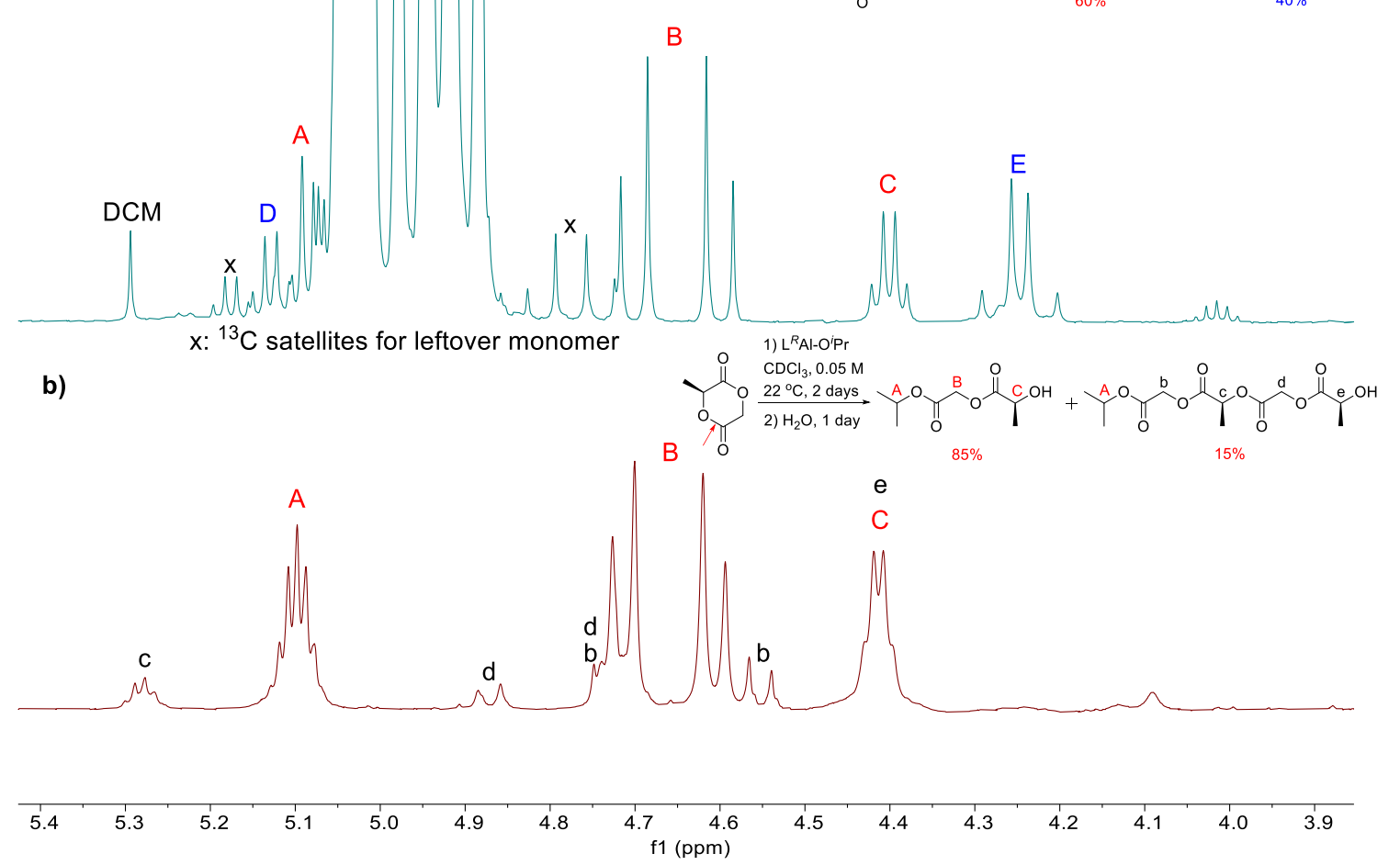

Figure S3. [Methyl-Glycolide $]_{0}:[\text { Initiator }]_{0}=1: 1$ ring-opening site determination. a) Opened non-selectively with $\mathrm{HO}^{i} \operatorname{Pr}$ at $50^{\circ} \mathrm{C}$, with conv. $=4 \%$. b) Opened selectively with (R)-(SalBinam) $\mathrm{AlO}^{i} \mathrm{Pr}$ in $\mathrm{CDCl}_{3}$ at $22^{\circ} \mathrm{C}$ and then quenched with a drop of $\mathrm{H}_{2} \mathrm{O}$, with conv. $=100 \%$. 


\subsection{Chain-end assignment}

Table 1, entry 16

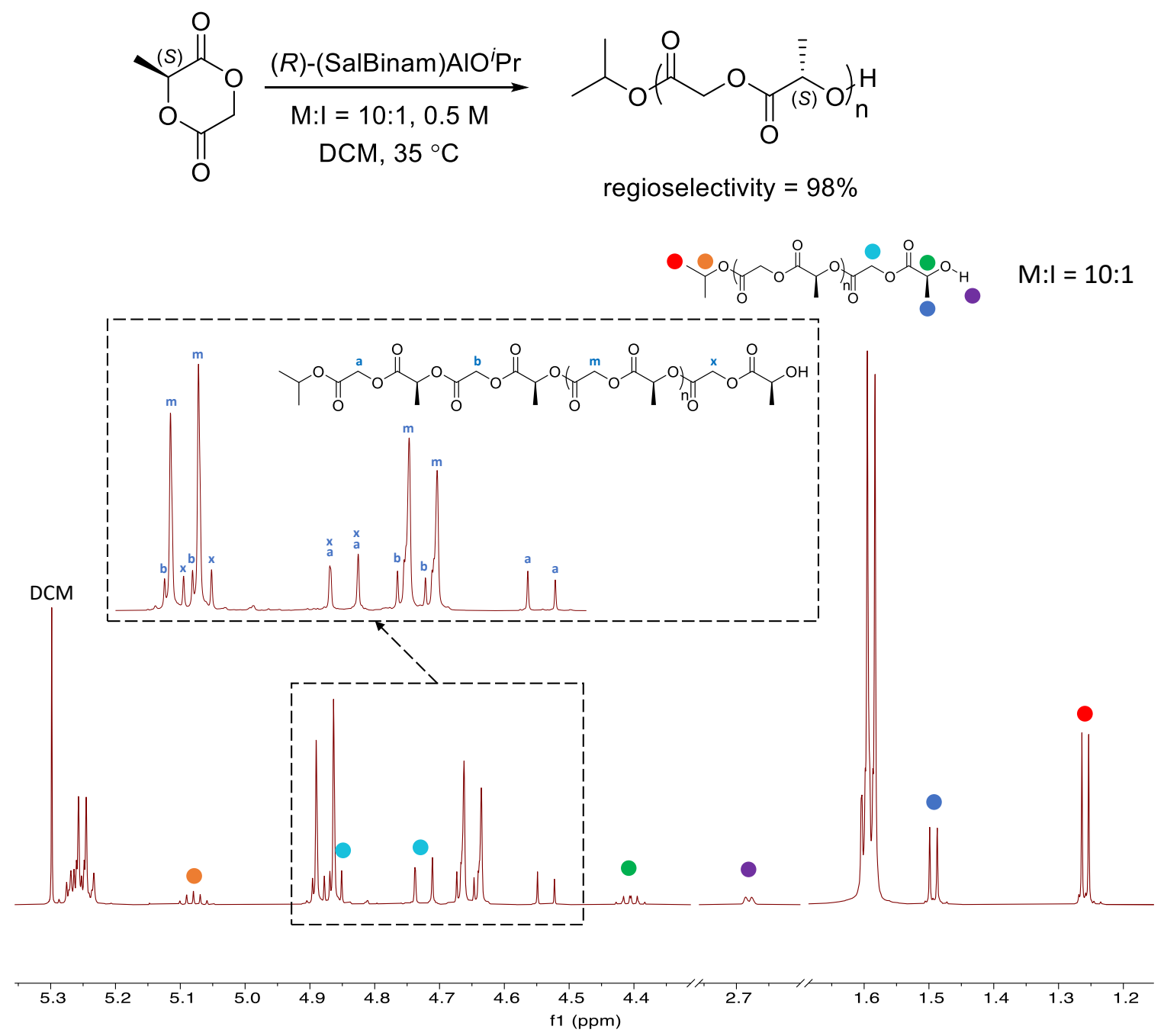

Figure S4. Polymer chain-end groups assignment with M:I = 10:1. 


\subsection{Regioselectivity calculation}

The polymer methylene region has two diastereotopic protons, featuring two doublets on NMR. In terms of the error insertion (labelled red in Figure 3b), the error $\mathrm{CH}_{2}$ diastereotopic protons lie in the regions of $\delta=4.80-4.85 \mathrm{ppm}$ and $\delta=4.71-4.76 \mathrm{ppm}$. Due to the integration feasibility and efficiency, only the $4.80-4.85 \mathrm{ppm}$ region is integrated and used for regioselectivity calculation. The $4.80-4.85 \mathrm{ppm}$ region represents one of the diastereotopic protons, so the integration should be half of the total error $\mathrm{CH}_{2}$ integration. Therefore, the regioselectivity calculation is given as below:

$$
\text { regioselectivity }=\left(1-\frac{2 \times S_{\text {err } / 2}}{S_{\text {all }}}\right) \times 100 \%
$$

Note that some sharp peaks within $4.50-4.90 \mathrm{ppm}$ are assigned to the chain ends, which are not considered as regioerror peaks, though they may partially overlap with each other. Chain ends typically include but are not limited to $\delta=4.52,4.55,4.71,4.74 \mathrm{ppm}$. See Figure S4 for full chain end assignment. 
Table 1, entry 7

$$
\text { regioselectivity }=\left(1-\frac{2 \times 1.00}{54.21}\right) \times 100 \%=96 \%
$$

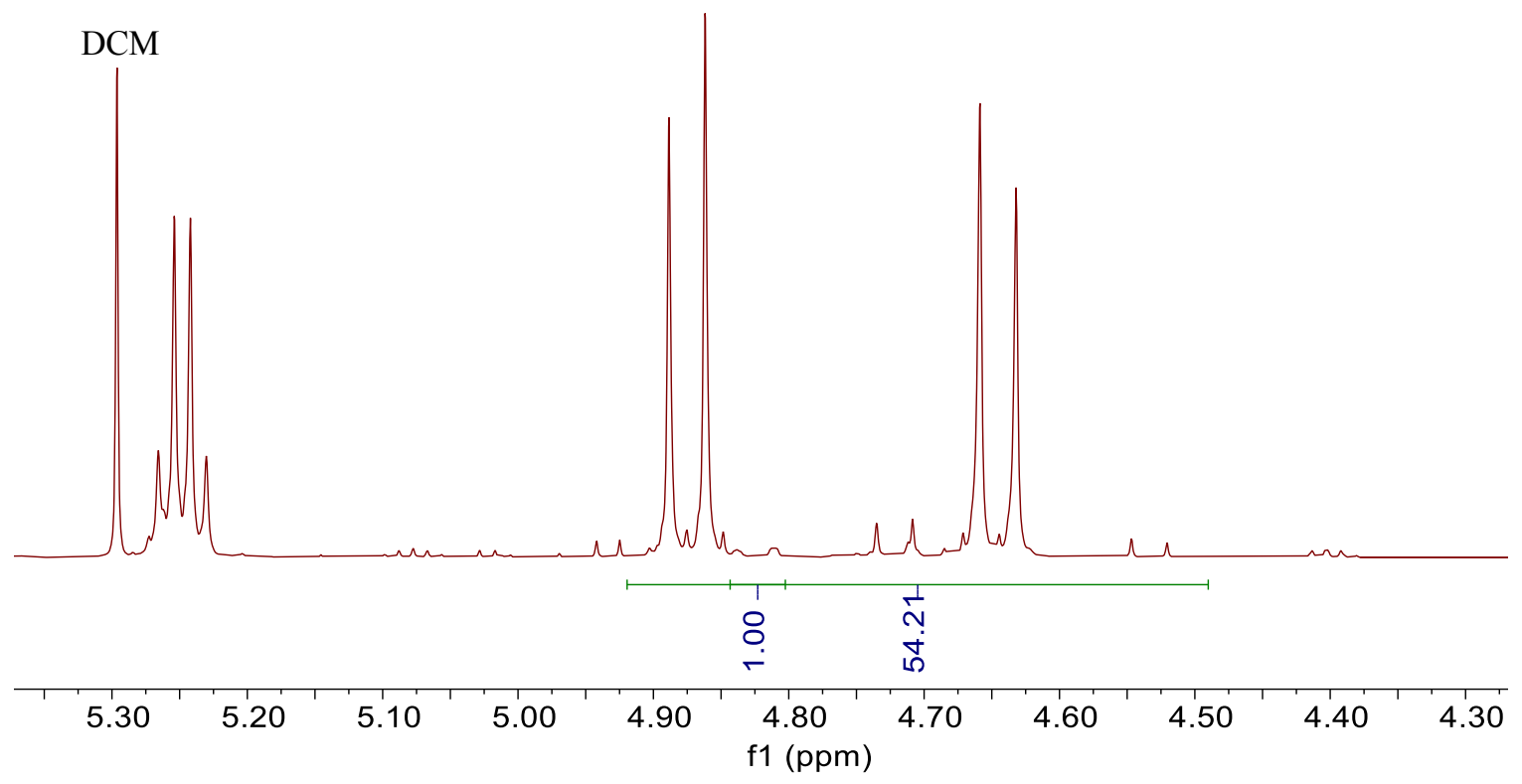

Figure S5. Sample calculation with regioselectivity $=96 \%$. 
Table S1, entry 14
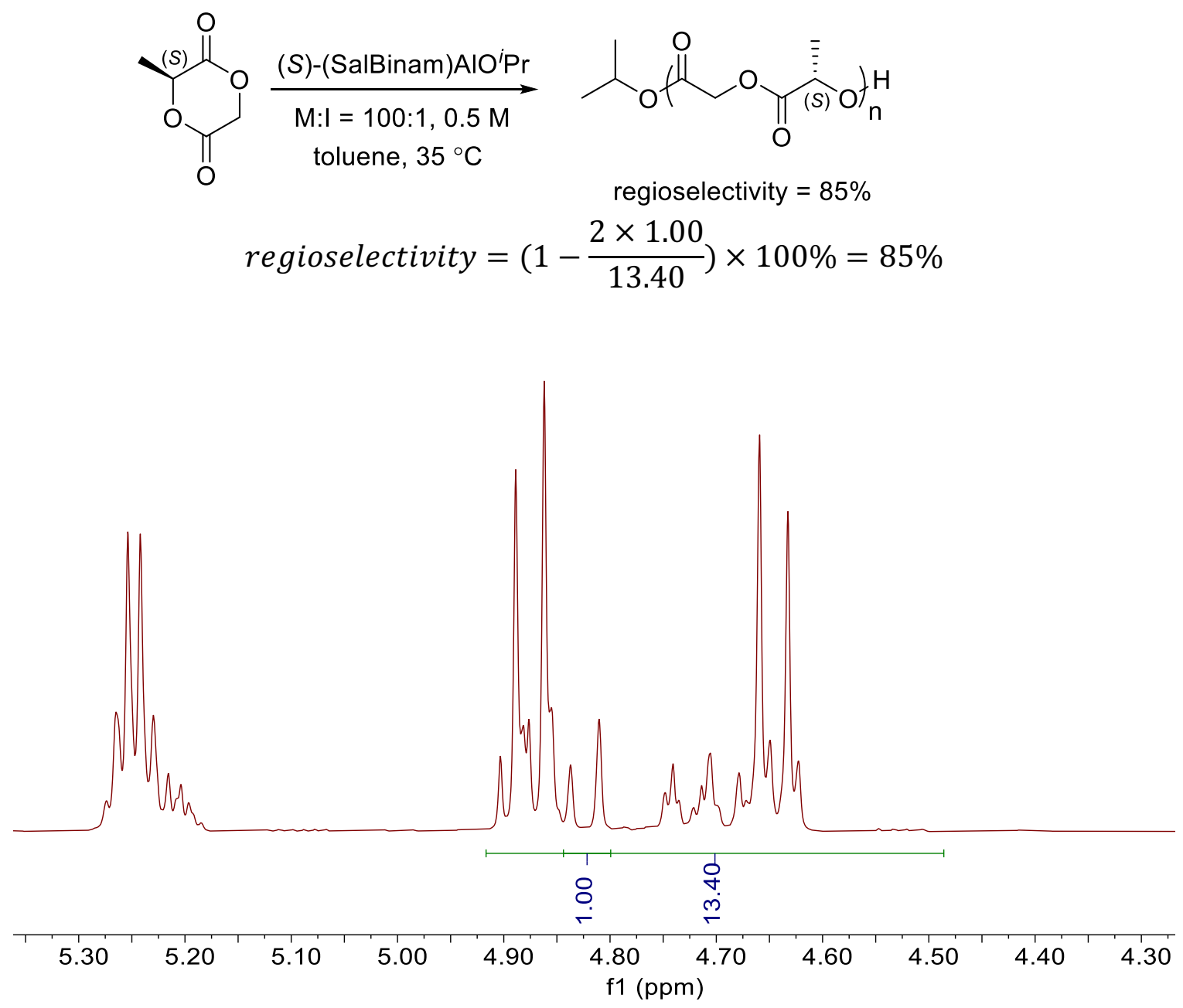

Figure S6. Sample calculation with regioselectivity $=85 \%$. 


\subsection{DSC data}

Representative DSC trace of alt-PLGA.

Table 1, entry 11
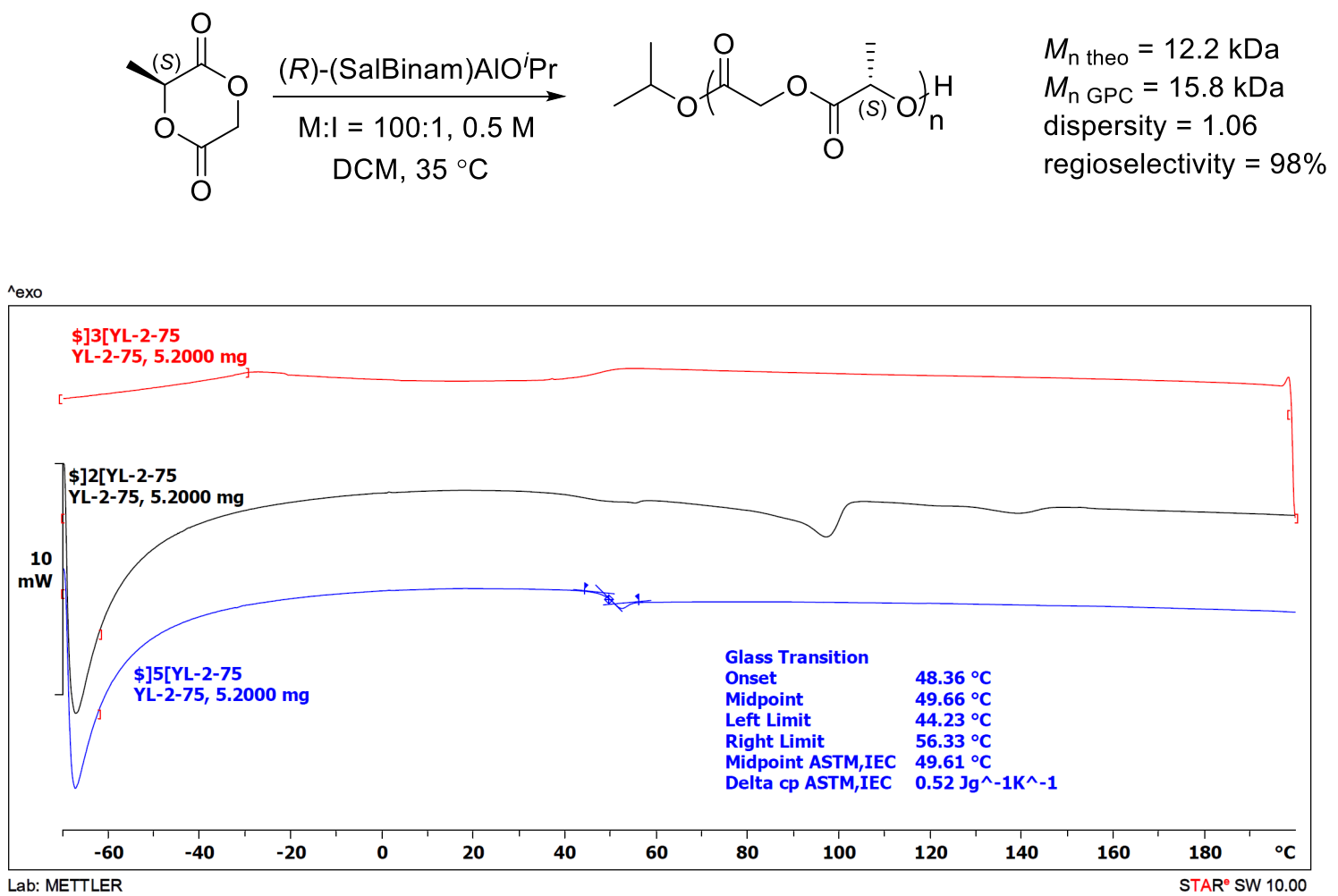

Figure S7. Polymer DSC analysis on the sample from Table 1, entry 11. Black - first heat;

Red - cool; Blue - second heat.

The glass transition temperature $\left(T_{\mathrm{g}}\right)$ was determined to be $50^{\circ} \mathrm{C} .\left(T_{\mathrm{g}}=50^{\circ} \mathrm{C}\right)$

No melting peak observed on the second heat. 


\subsection{GPC data}

Representative GPC trace of alt-PLGA.

Table 1, entry 11

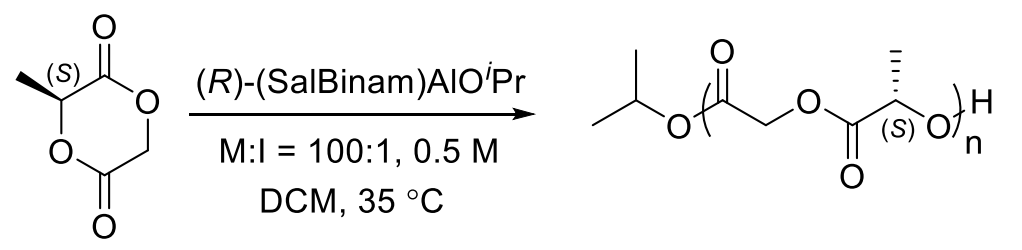

$$
\begin{aligned}
& M_{\mathrm{n} \text { theo }}=12.2 \mathrm{kDa} \\
& M_{\mathrm{n} G \mathrm{CPC}}=15.8 \mathrm{kDa} \\
& \text { dispersity }=1.06 \\
& \text { regioselectivity }=98 \%
\end{aligned}
$$

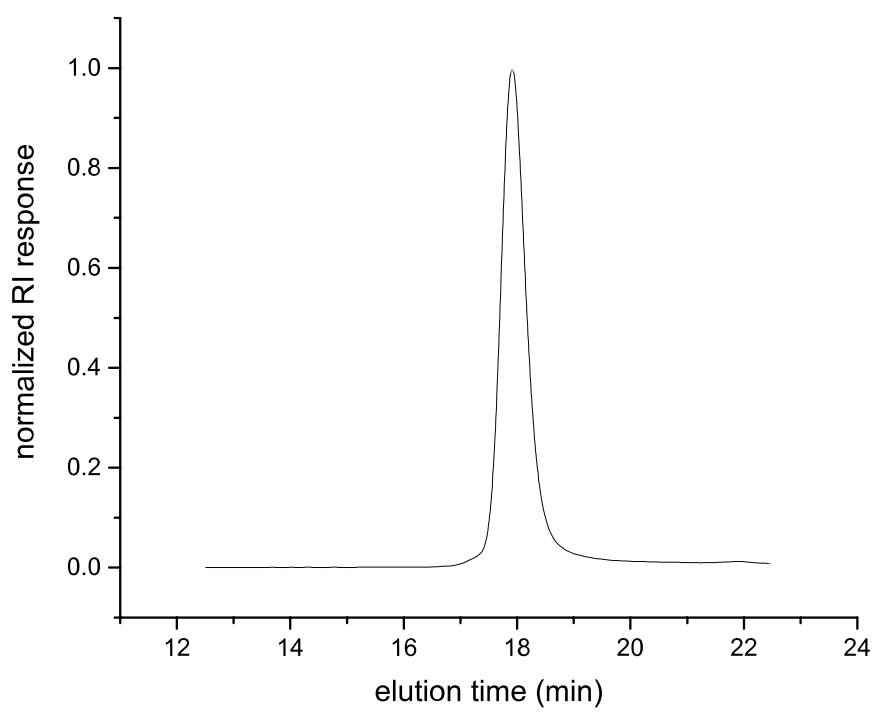

Figure S8. Polymer GPC trace of the sample from Table 1, entry 11. 
4.8 Proposed mechanism

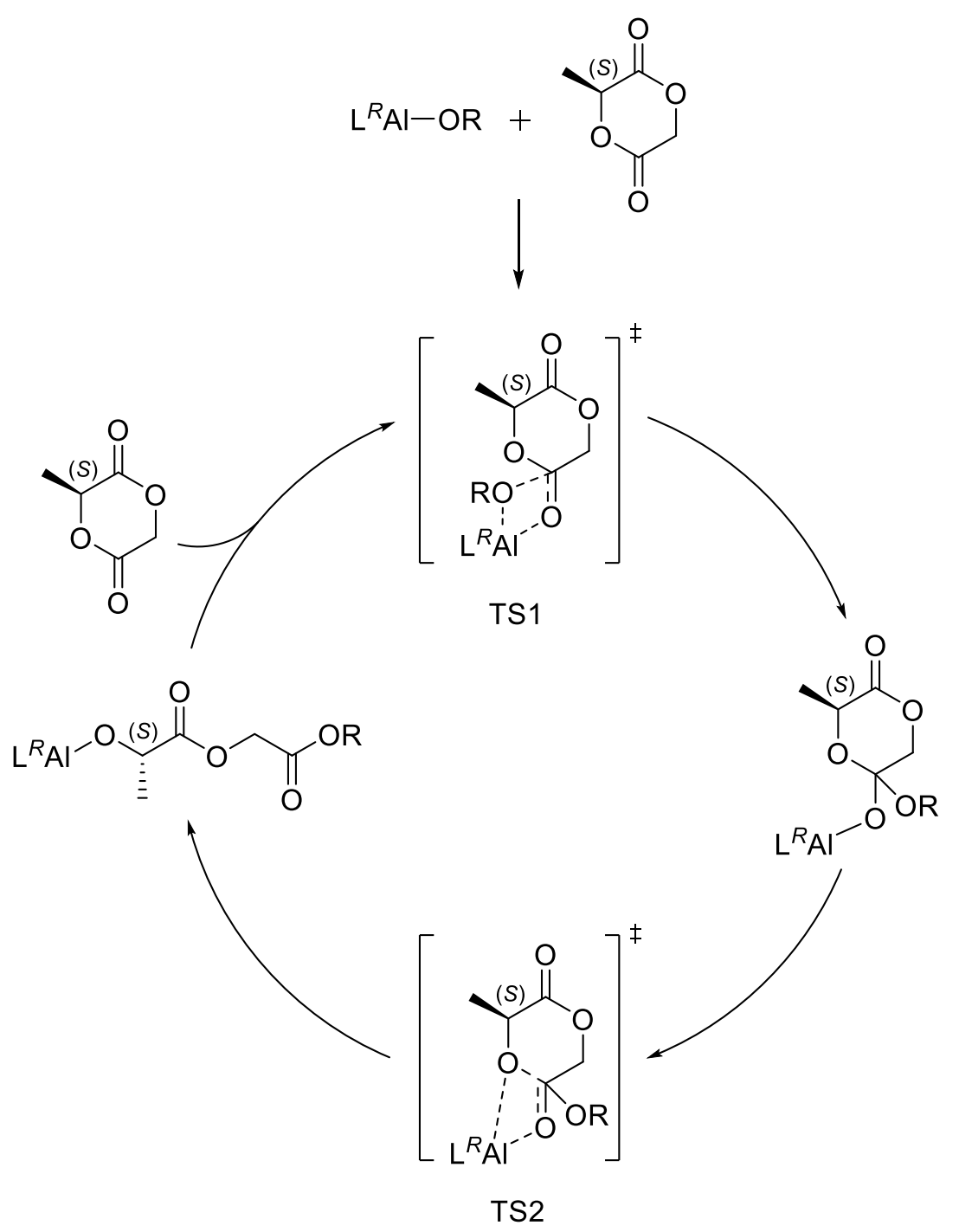

Figure S9. Coordination insertion mechanism. ${ }^{7}$ 


\section{$5{ }^{1} \mathrm{H}$ and ${ }^{13} \mathrm{C}$ NMR Spectra}

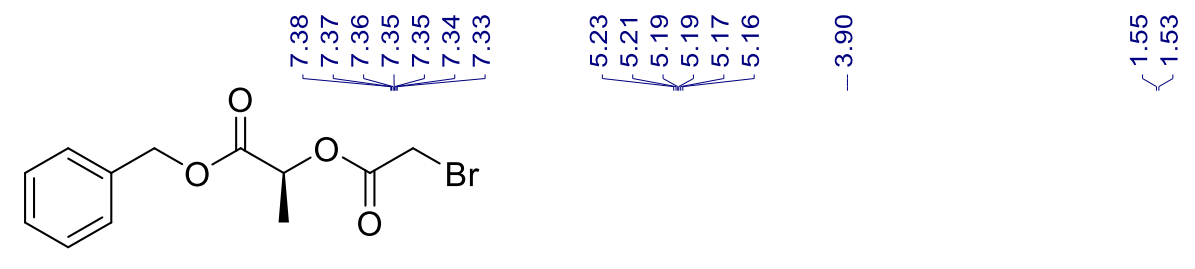

s1

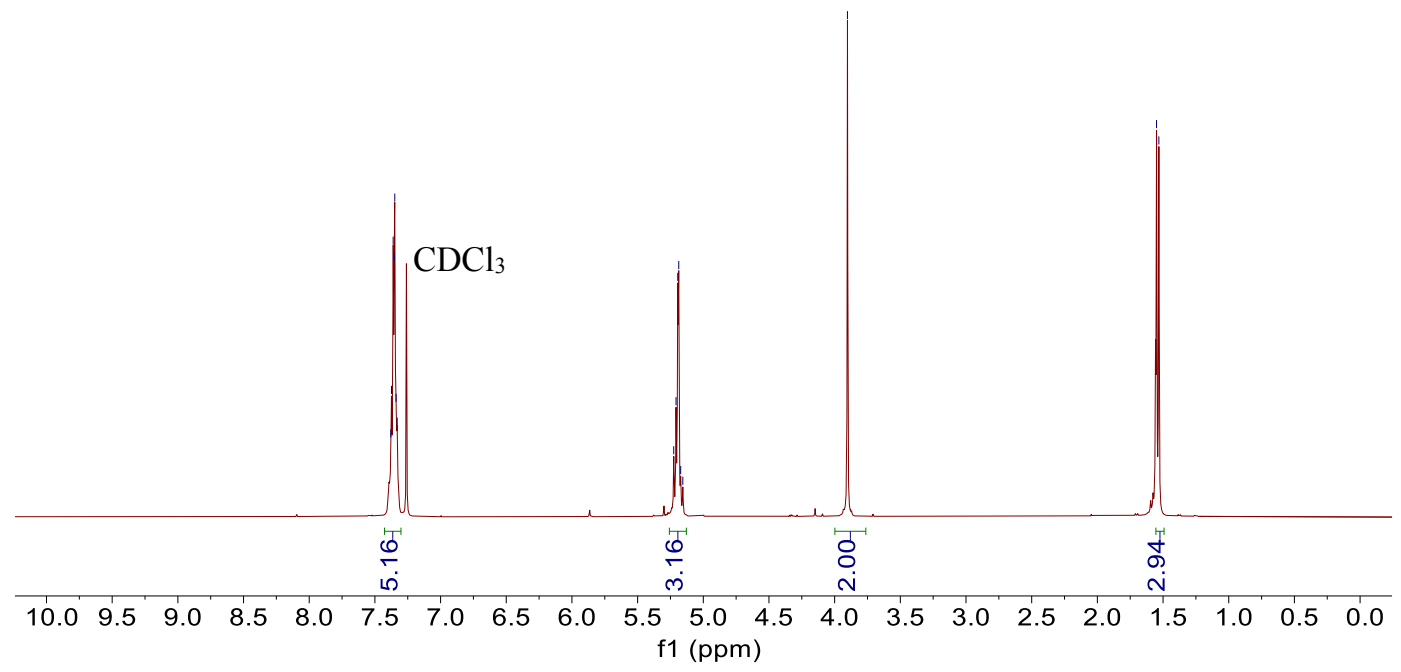

Figure S10. ${ }^{1} \mathrm{H}$ NMR (400 $\left.\mathrm{MHz}, \mathrm{CDCl}_{3}\right)$ spectrum of $\mathbf{S 1}$.

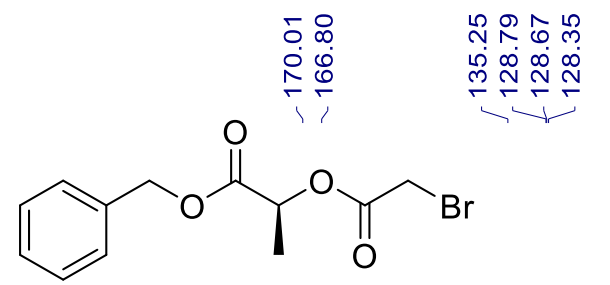

S1

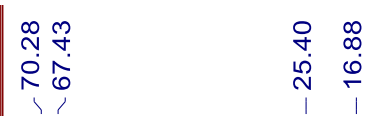

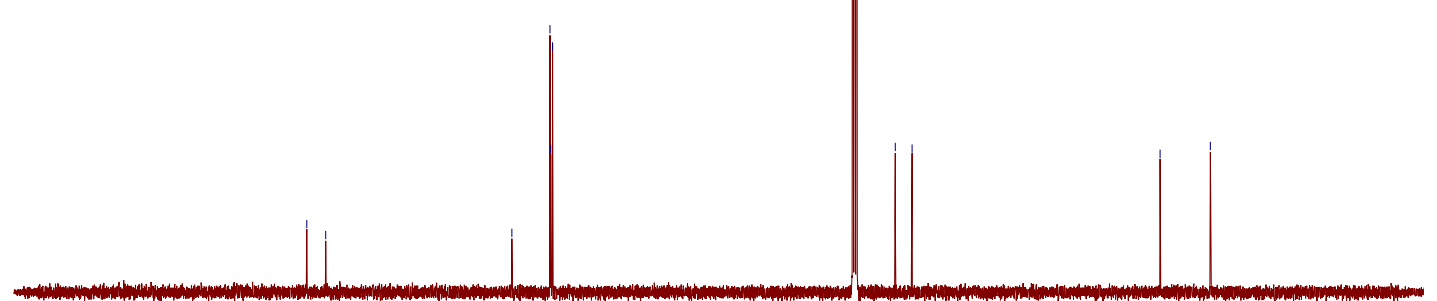

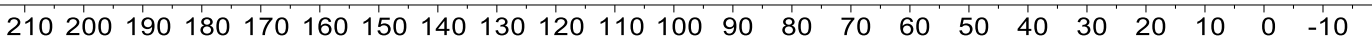
f1 (ppm)

Figure S11. ${ }^{13} \mathrm{C}$ NMR $\left(100 \mathrm{MHz}, \mathrm{CDCl}_{3}\right)$ spectrum of $\mathbf{S 1}$. 


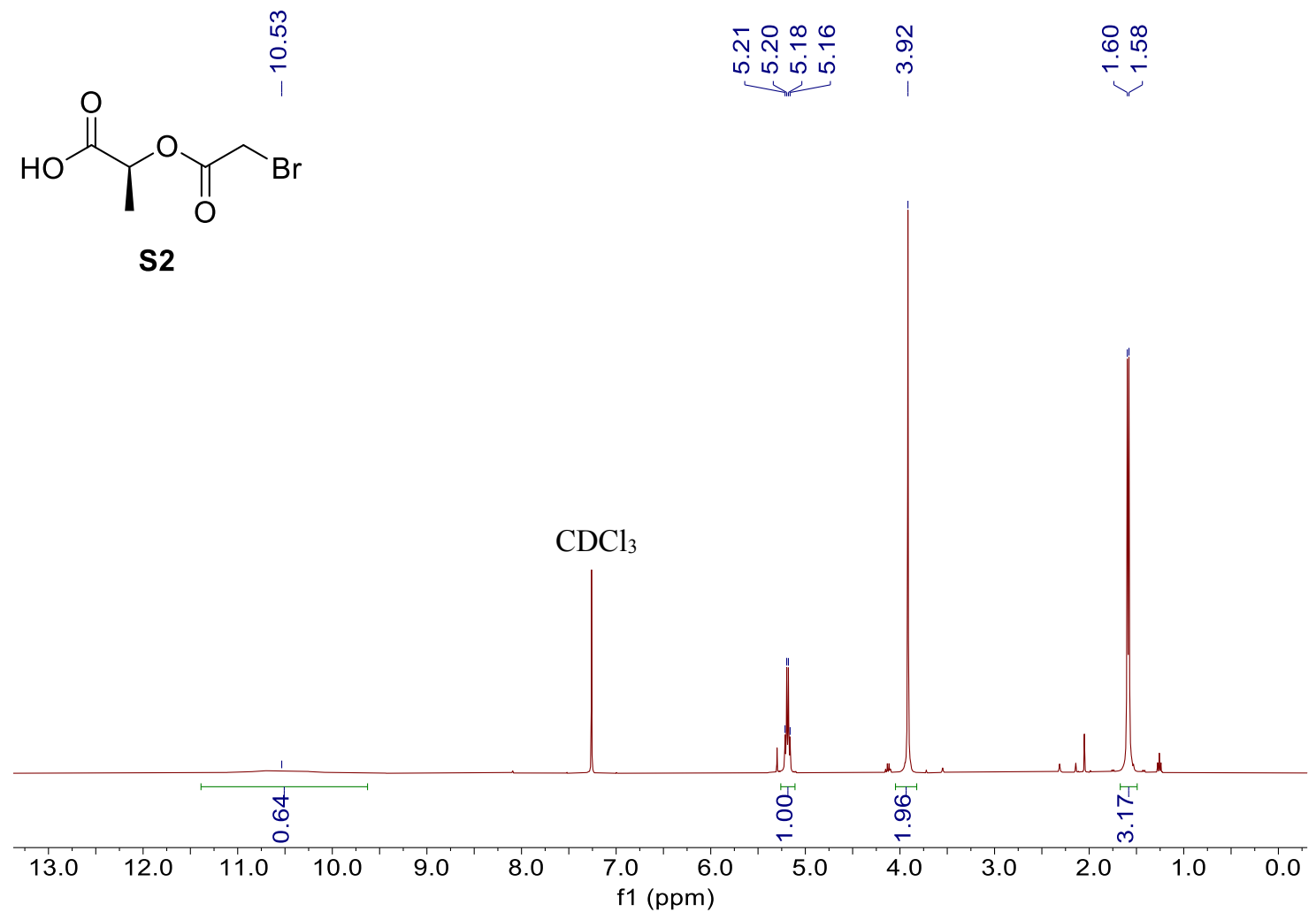

Figure S12. ${ }^{1} \mathrm{H}$ NMR (400 $\left.\mathrm{MHz}, \mathrm{CDCl}_{3}\right)$ spectrum of $\mathbf{S 2}$.

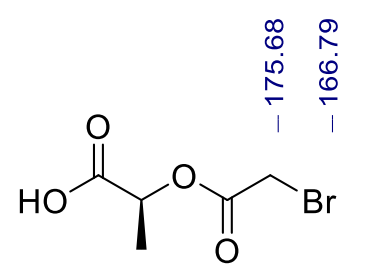

S2
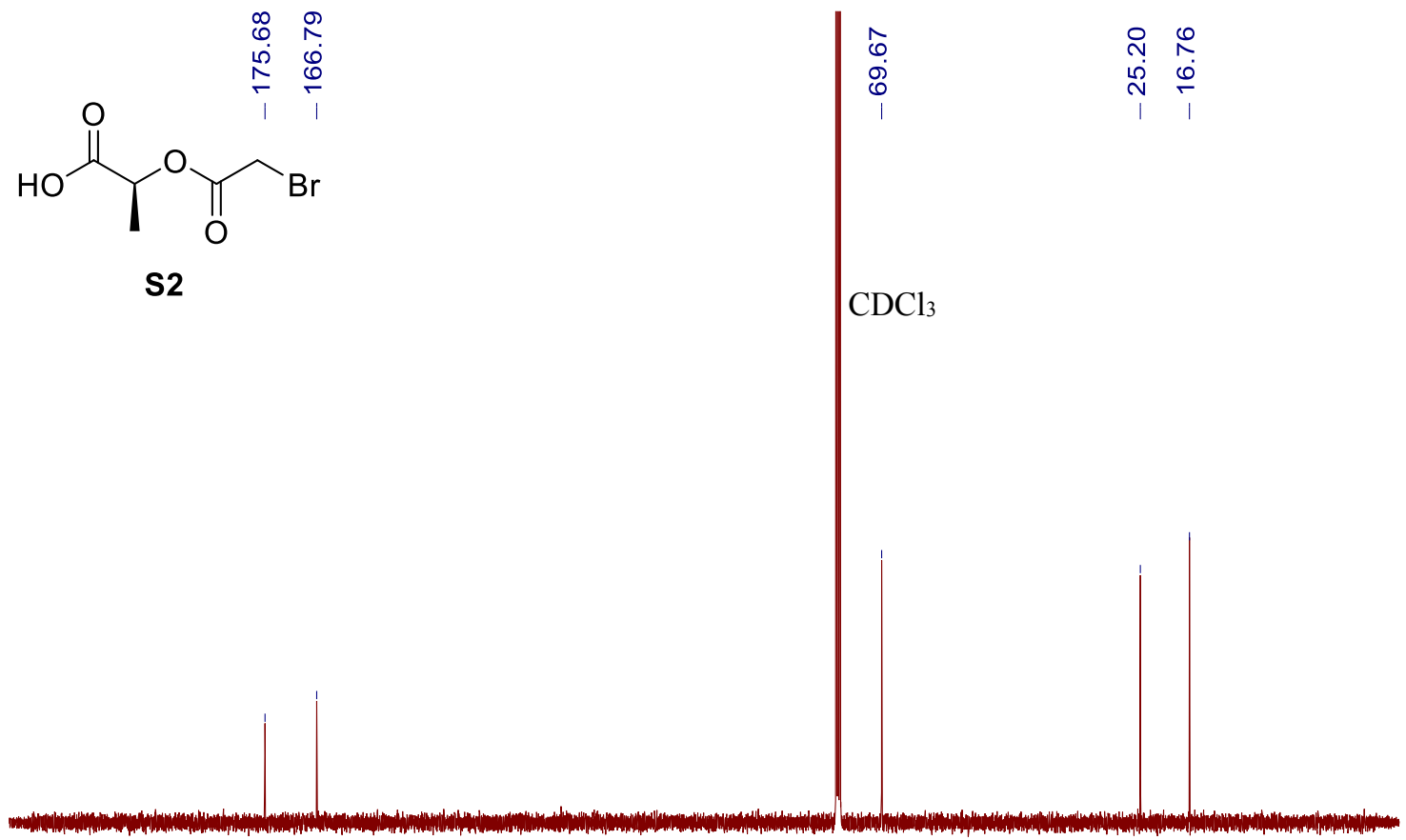

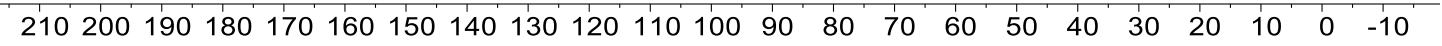
f1 (ppm)

Figure S13. ${ }^{13} \mathrm{C}$ NMR $\left(100 \mathrm{MHz}, \mathrm{CDCl}_{3}\right)$ spectrum of $\mathbf{S 2}$. 
<smiles>C[C@H]1OC(=O)COC1=O</smiles>

S3

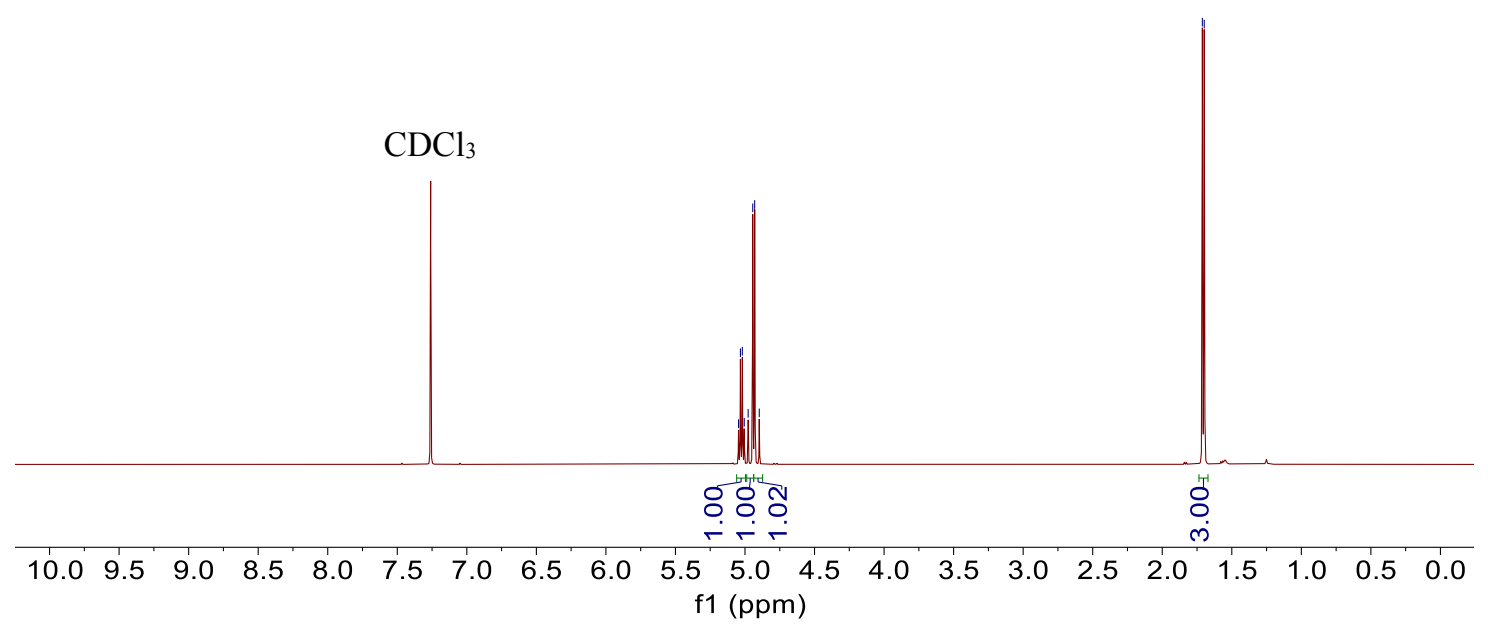

Figure S14. ${ }^{1} \mathrm{H}$ NMR $\left(500 \mathrm{MHz}, \mathrm{CDCl}_{3}\right)$ spectrum of $\mathbf{S 3}$.<smiles>C[C@H]1OC(=O)COC1=O</smiles>

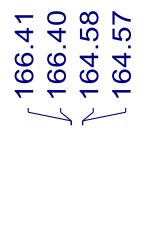

ஸุ

ำ

กิ

S3

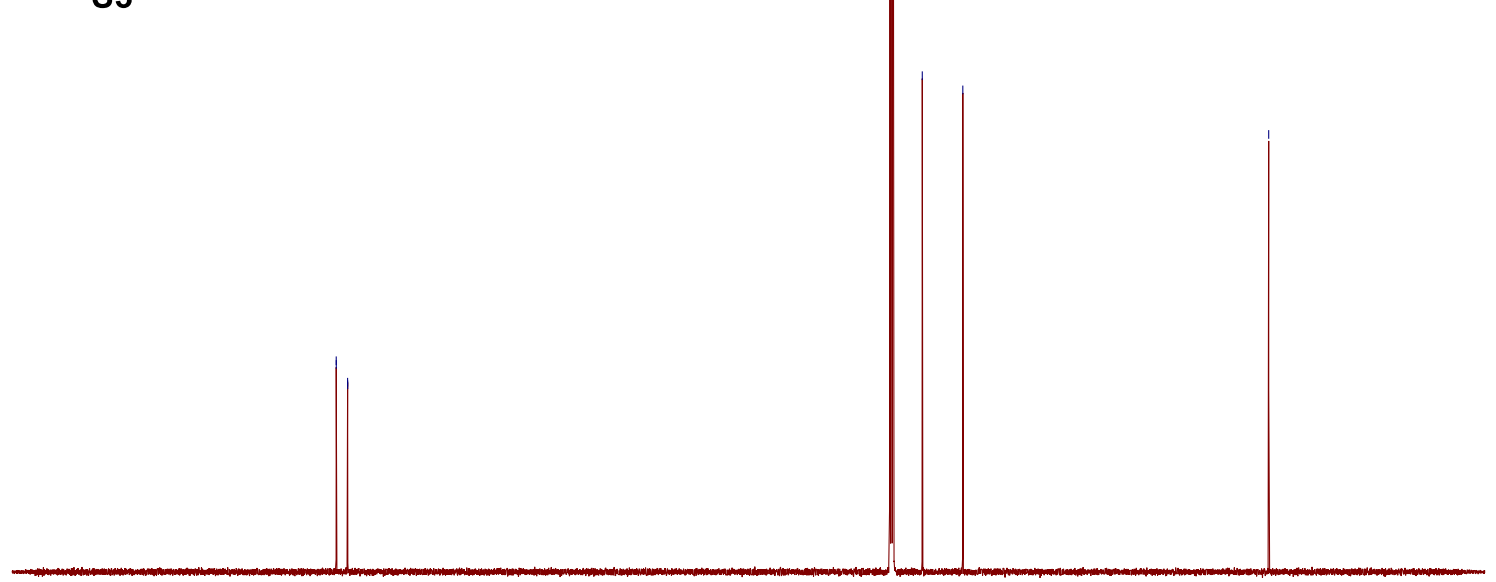

$\mathrm{CDCl}_{3}$

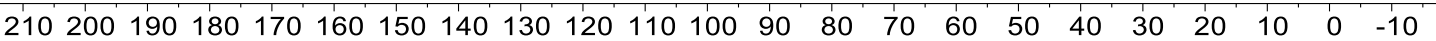
f1 (ppm) 
Figure S15. ${ }^{13} \mathrm{C}$ NMR (125 $\left.\mathrm{MHz}, \mathrm{CDCl}_{3}\right)$ spectrum of $\mathbf{S 3}$.

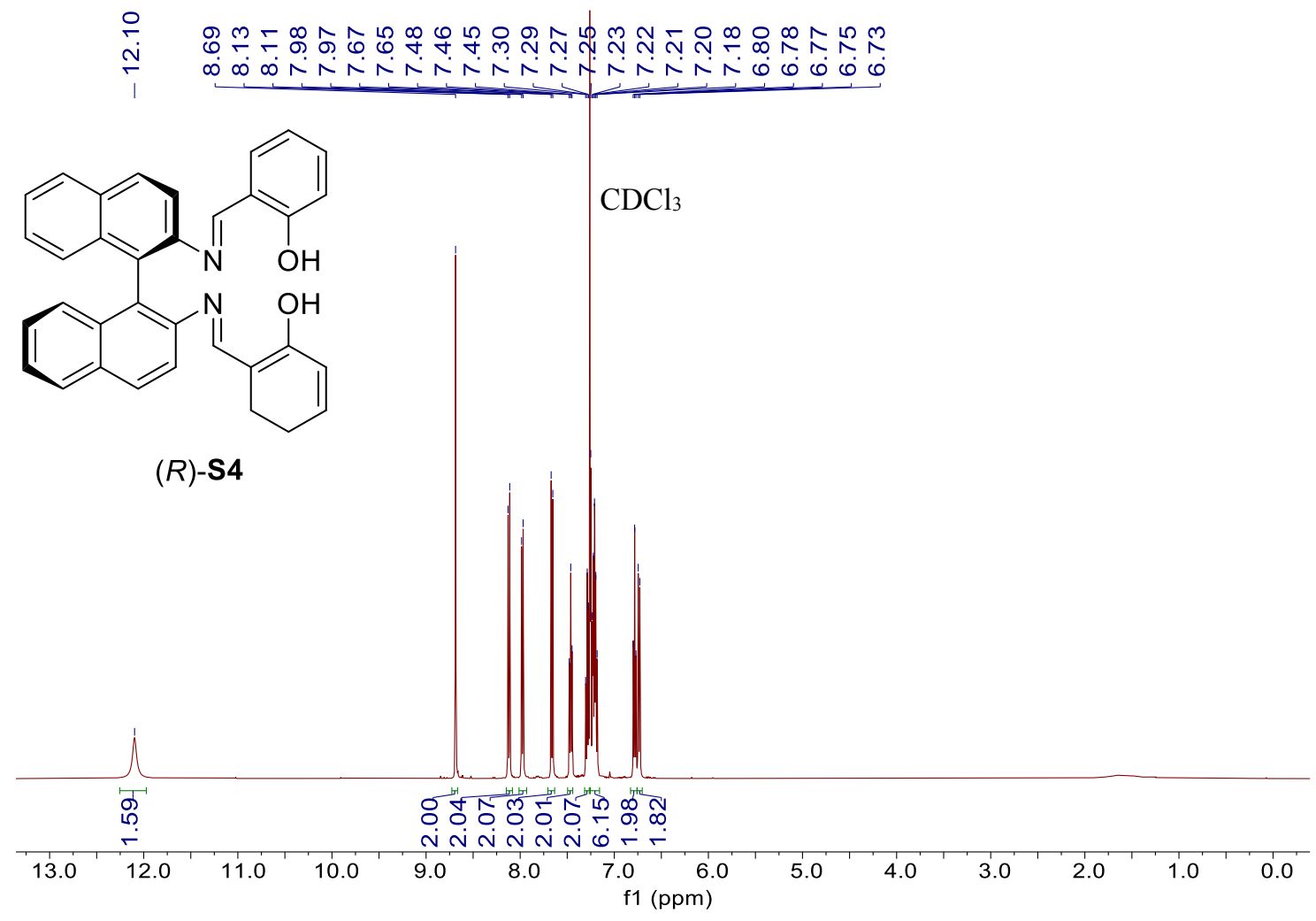

Figure S16. ${ }^{1} \mathrm{H} \mathrm{NMR}\left(500 \mathrm{MHz}, \mathrm{CDCl}_{3}\right)$ spectrum of $(R)-\mathbf{S 4}$.

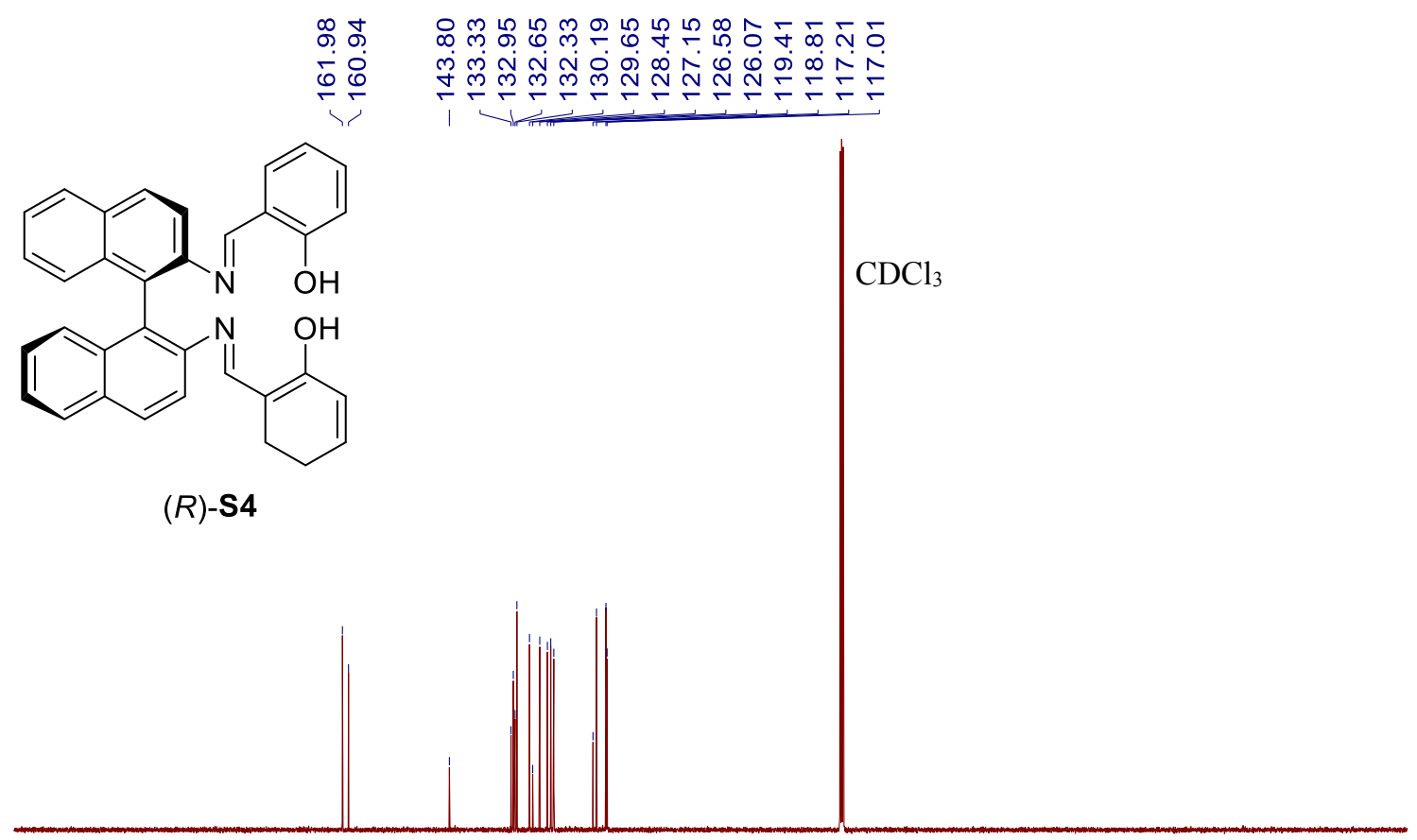

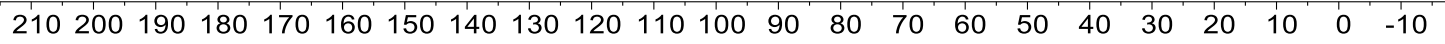
f1 (ppm) 
Figure S17. ${ }^{13} \mathrm{C}$ NMR $\left(125 \mathrm{MHz}, \mathrm{CDCl}_{3}\right)$ spectrum of $(R)-\mathbf{S} 4$.

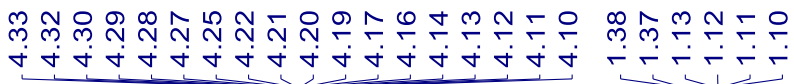

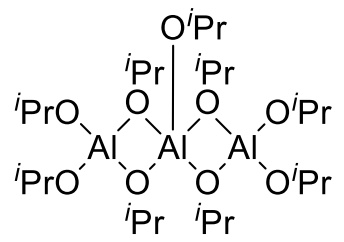

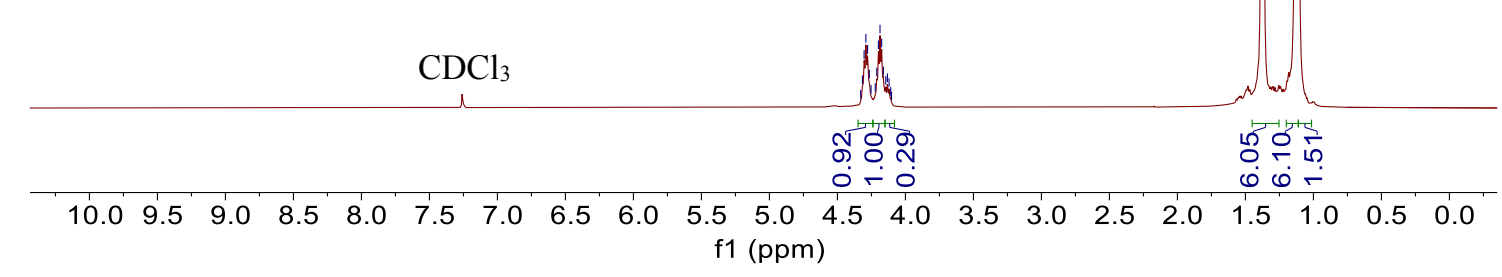

Figure S18. ${ }^{1} \mathrm{H}$ NMR $\left(500 \mathrm{MHz}, \mathrm{CDCl}_{3}\right)$ spectrum of trimeric $\mathrm{Al}\left(\mathrm{O}^{i} \mathrm{Pr}\right)_{3}$ after heating.

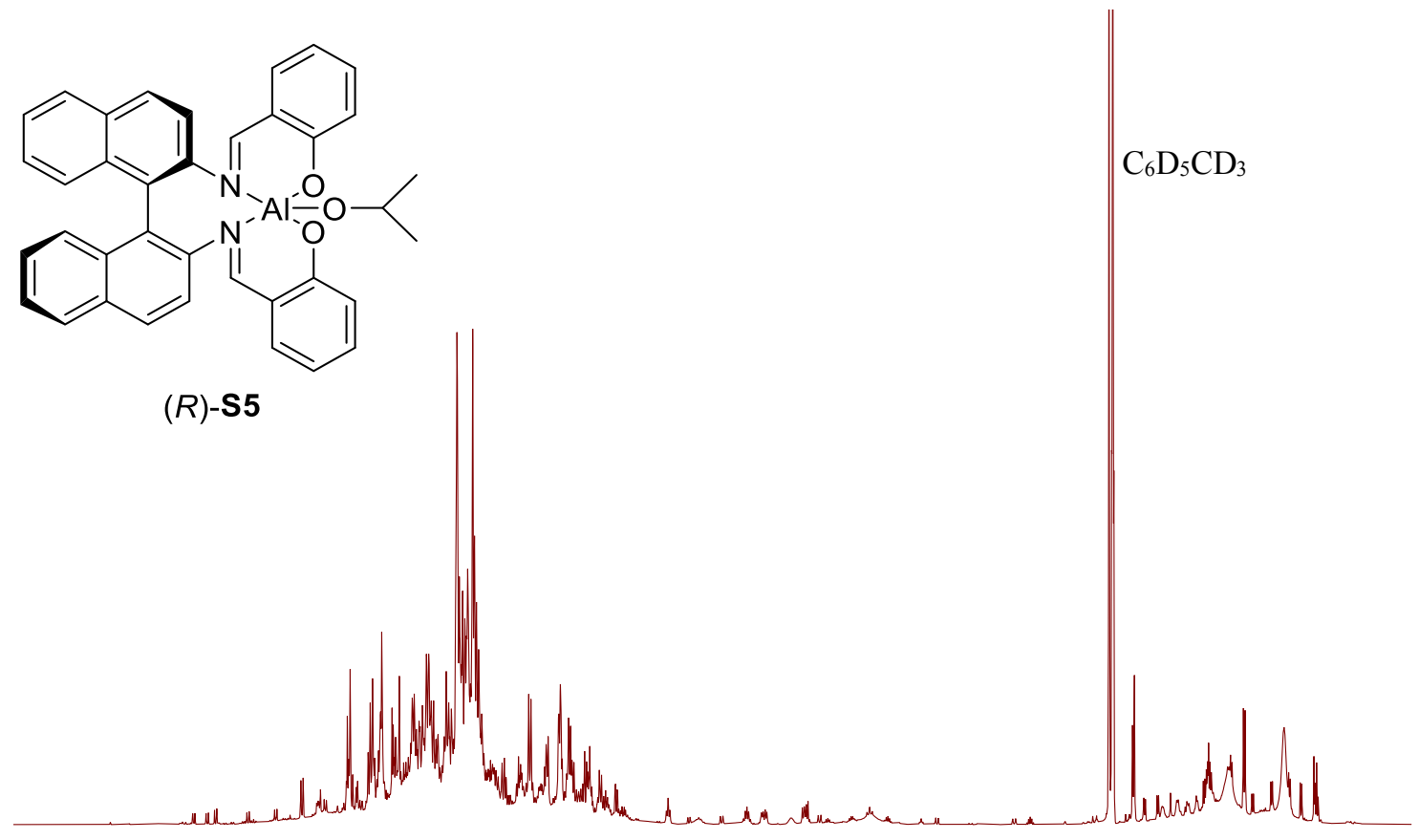

$\begin{array}{llllllllllllllllllllll}10.0 & 9.5 & 9.0 & 8.5 & 8.0 & 7.5 & 7.0 & 6.5 & 6.0 & 5.5 & 5.0 & 4.5 & 4.0 & 3.5 & 3.0 & 2.5 & 2.0 & 1.5 & 1.0 & 0.5 & 0.0\end{array}$ f1 (ppm)

S27 
Figure S19. ${ }^{1} \mathrm{H}$ NMR (500 MHz, $\left.\mathrm{C}_{6} \mathrm{D}_{5} \mathrm{CD}_{3}\right)$ spectrum of $(R)-\mathbf{S 5}$.<smiles>CC(C)OC(=O)COC(=O)[C@H](C)[OH+]</smiles>

ล

ம் மூ

\section{实}

regioselectivity $=98 \%$

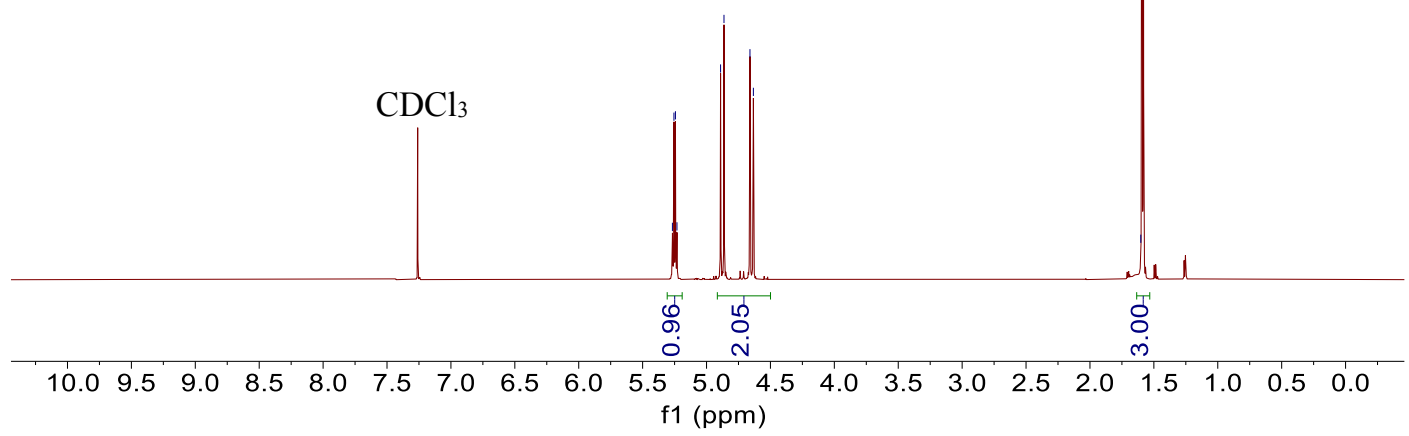

Figure S20. ${ }^{1} \mathrm{H}$ NMR $\left(600 \mathrm{MHz}, \mathrm{CDCl}_{3}\right)$ spectrum of alt-PLGA (regioselectivity = 98\%). See Figure S1 (top) for expanded regions.
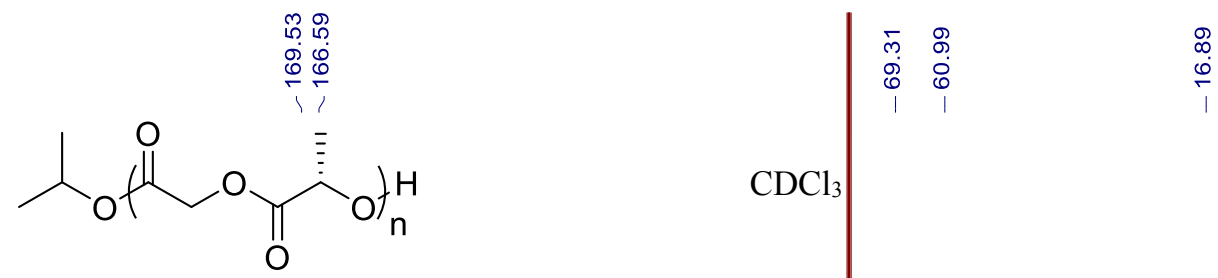

regioselectivity $=98 \%$ 
Figure S21. ${ }^{13} \mathrm{C}$ NMR $\left(125 \mathrm{MHz}, \mathrm{CDCl}_{3}\right)$ spectrum of alt-PLGA (regioselectivity =98\%). See Figure S2 (top) for expanded regions.

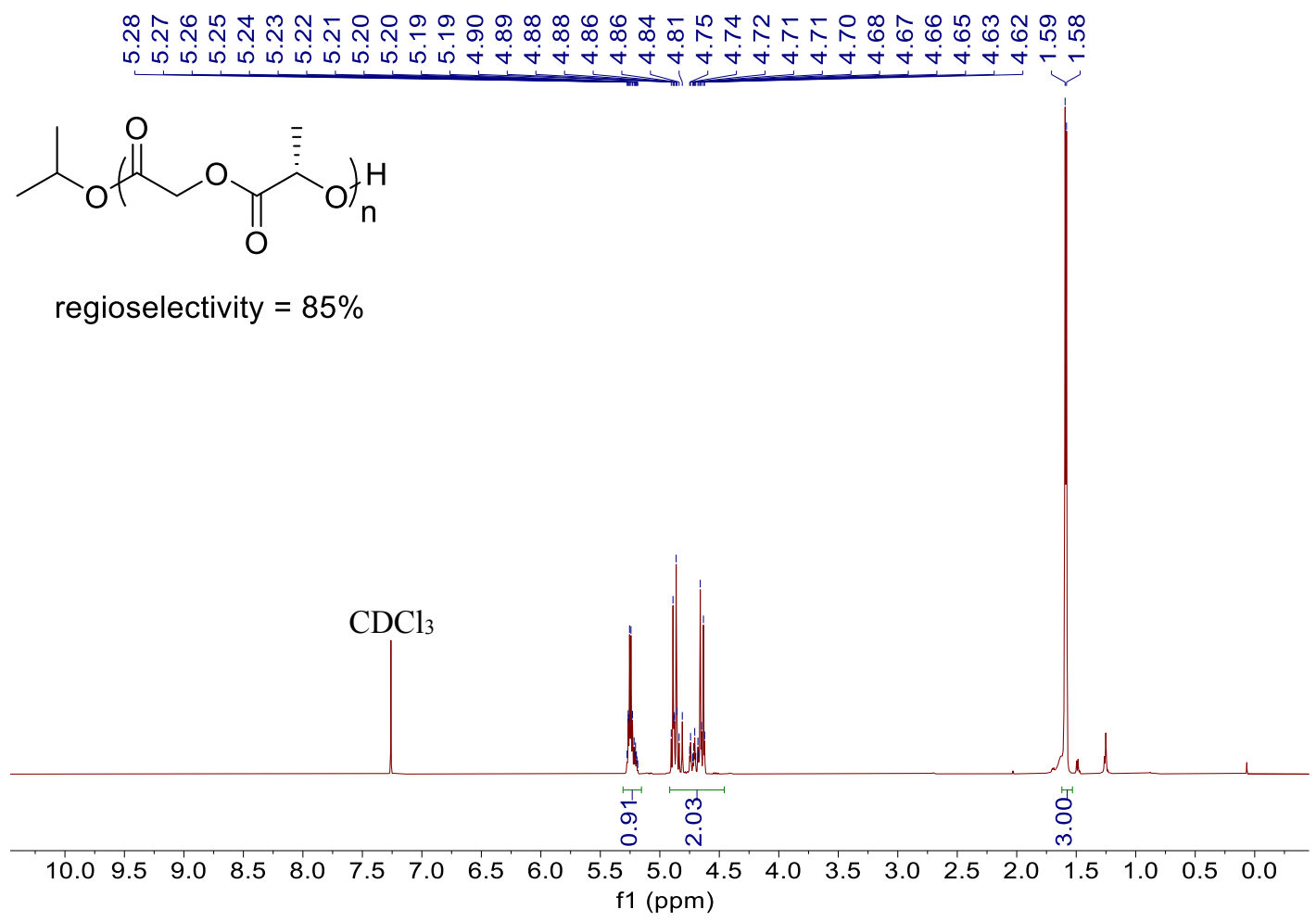

Figure S22. ${ }^{1} \mathrm{H}$ NMR $\left(600 \mathrm{MHz}, \mathrm{CDCl}_{3}\right)$ spectrum of alt-PLGA (regioselectivity $=85 \%$ ). See Figure S1 (bottom) for expanded regions.

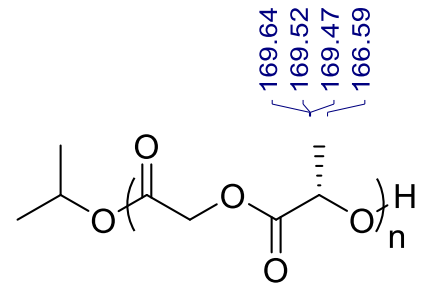

regioselectivity $=85 \%$

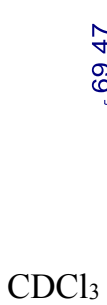

일

:

4

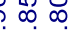

$\dot{\varphi} \div \dot{\varphi}$

$\mathrm{CDCl}_{3}$

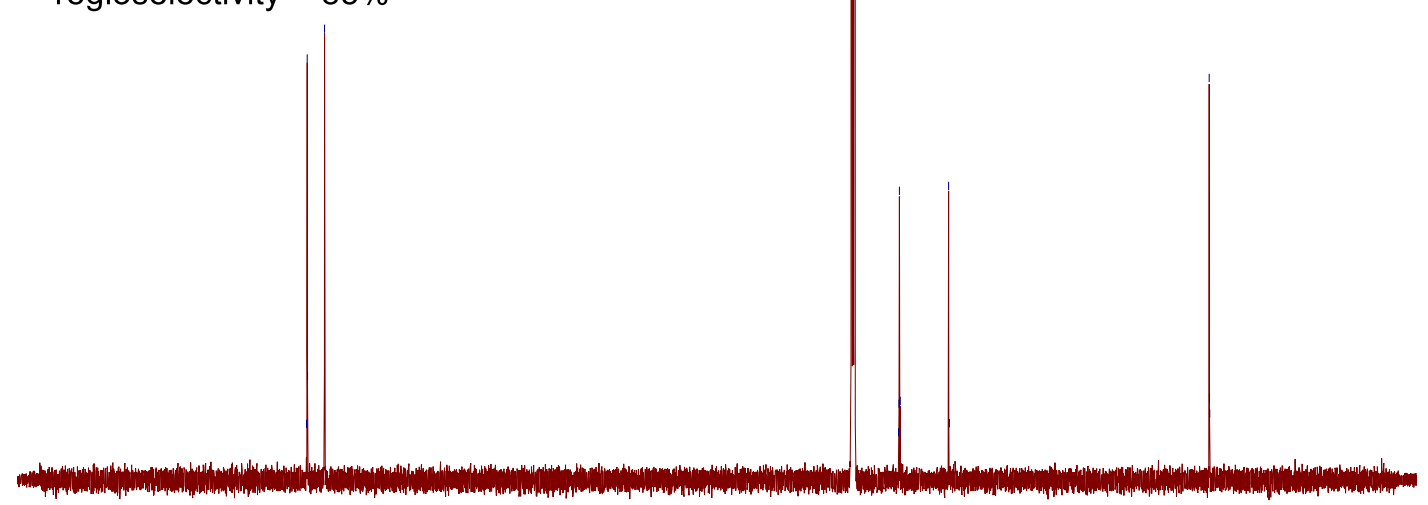

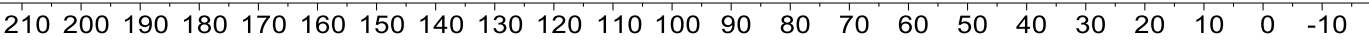


Figure S23. ${ }^{13} \mathrm{C}$ NMR $\left(125 \mathrm{MHz}, \mathrm{CDCl}_{3}\right)$ spectrum of alt-PLGA (regioselectivity $=85 \%$ ). See Figure S2 (bottom) for expanded regions.

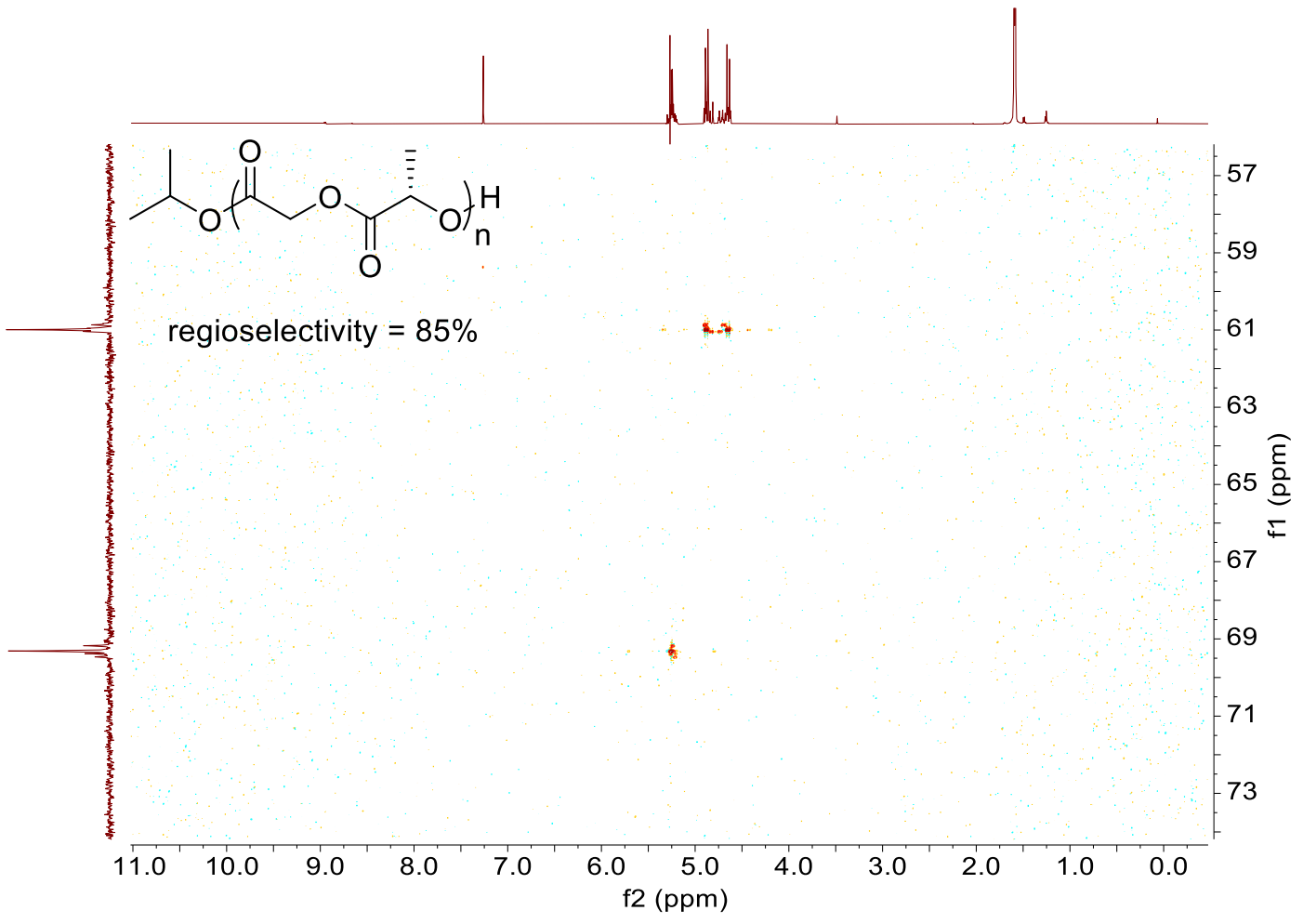

Figure S24. Band-selective HSQC $\left(600 / 150 \mathrm{MHz}, \mathrm{CDCl}_{3}\right)$ of alt-PLGA (regioselectivity $=85 \%)$.

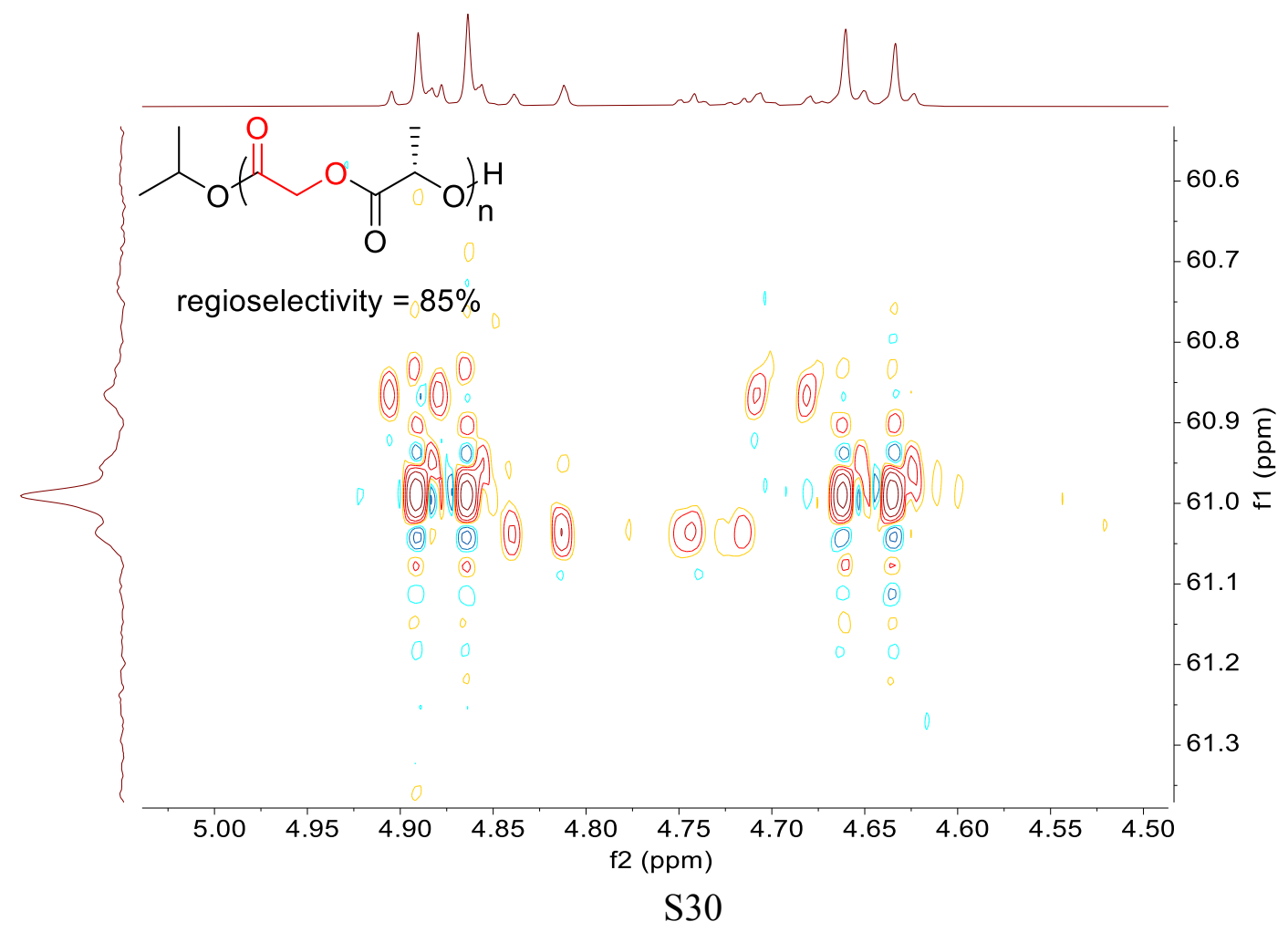


Figure S25. Glycolic unit region (expanded) from band-selective HSQC (600/150 MHz, $\mathrm{CDCl}_{3}$ ) of alt-PLGA (regioselectivity $=85 \%$ ).

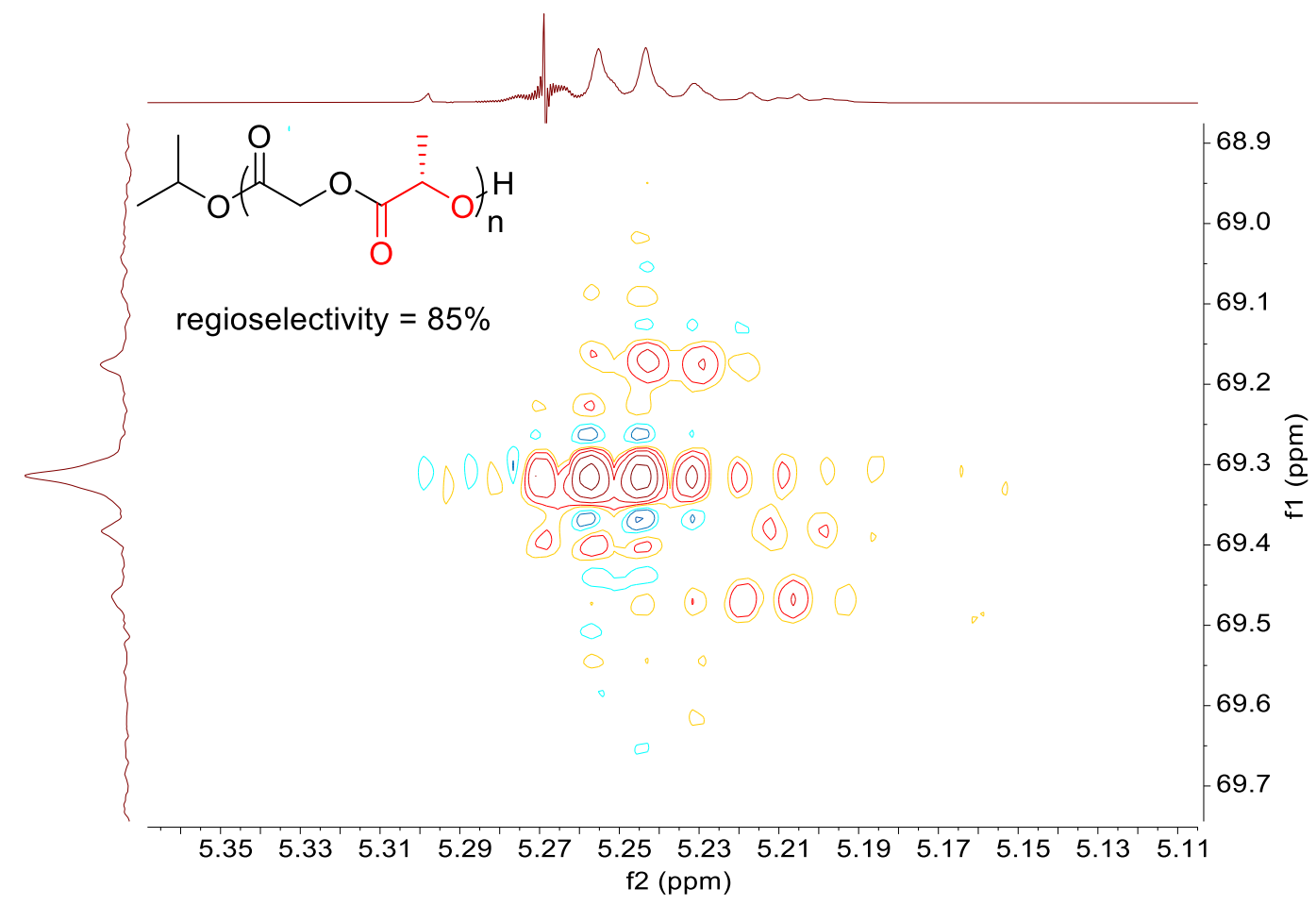

Figure S26. Lactic unit region (expanded) from band-selective HSQC (600/150 MHz, $\mathrm{CDCl}_{3}$ ) of alt-PLGA (regioselectivity $=85 \%$ ).

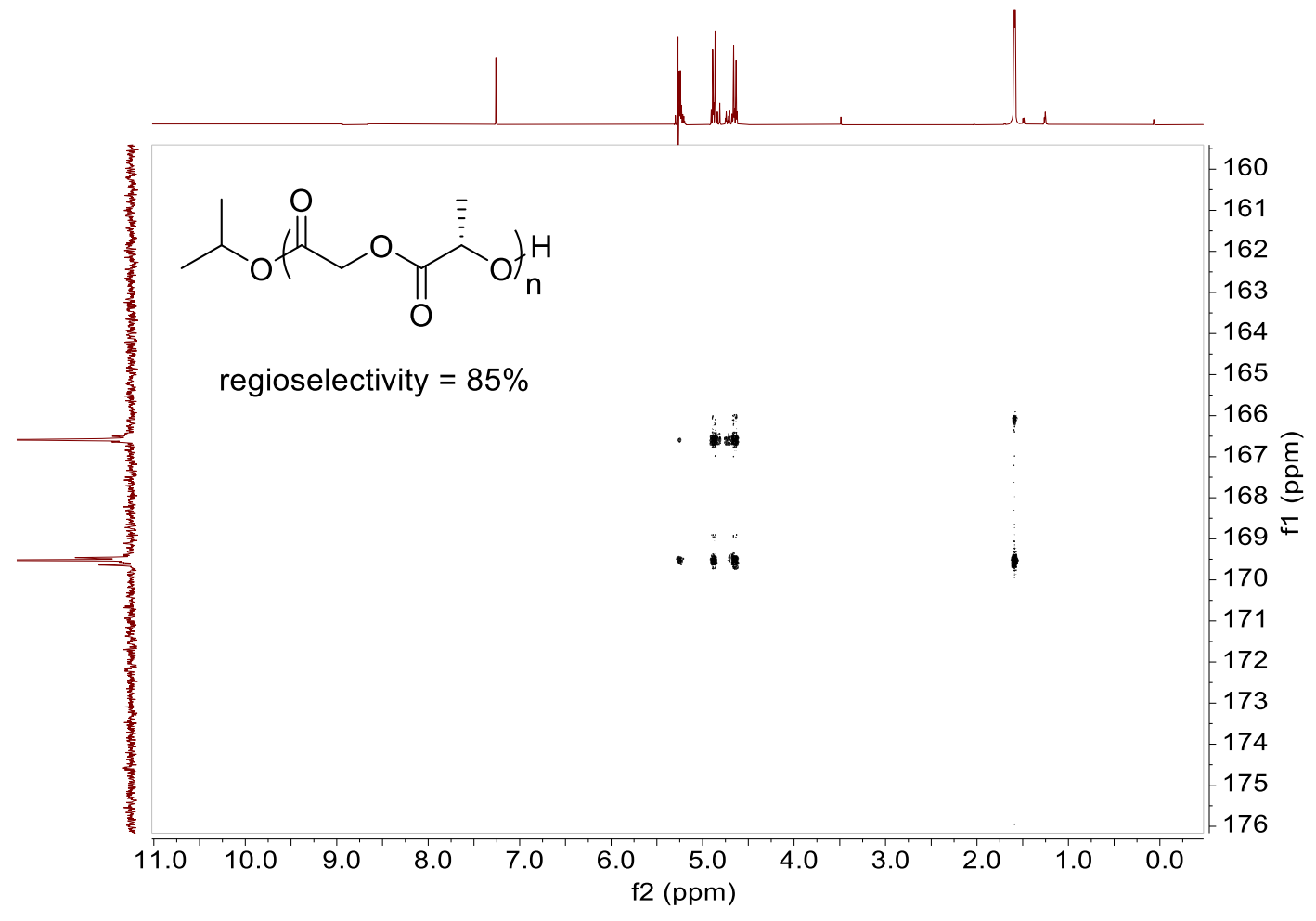


Figure S27. Band-selective $\mathrm{HMBC}\left(600 / 150 \mathrm{MHz} \mathrm{CDCl}_{3}\right)$ of alt-PLGA (regioselectivity $=85 \%)$.

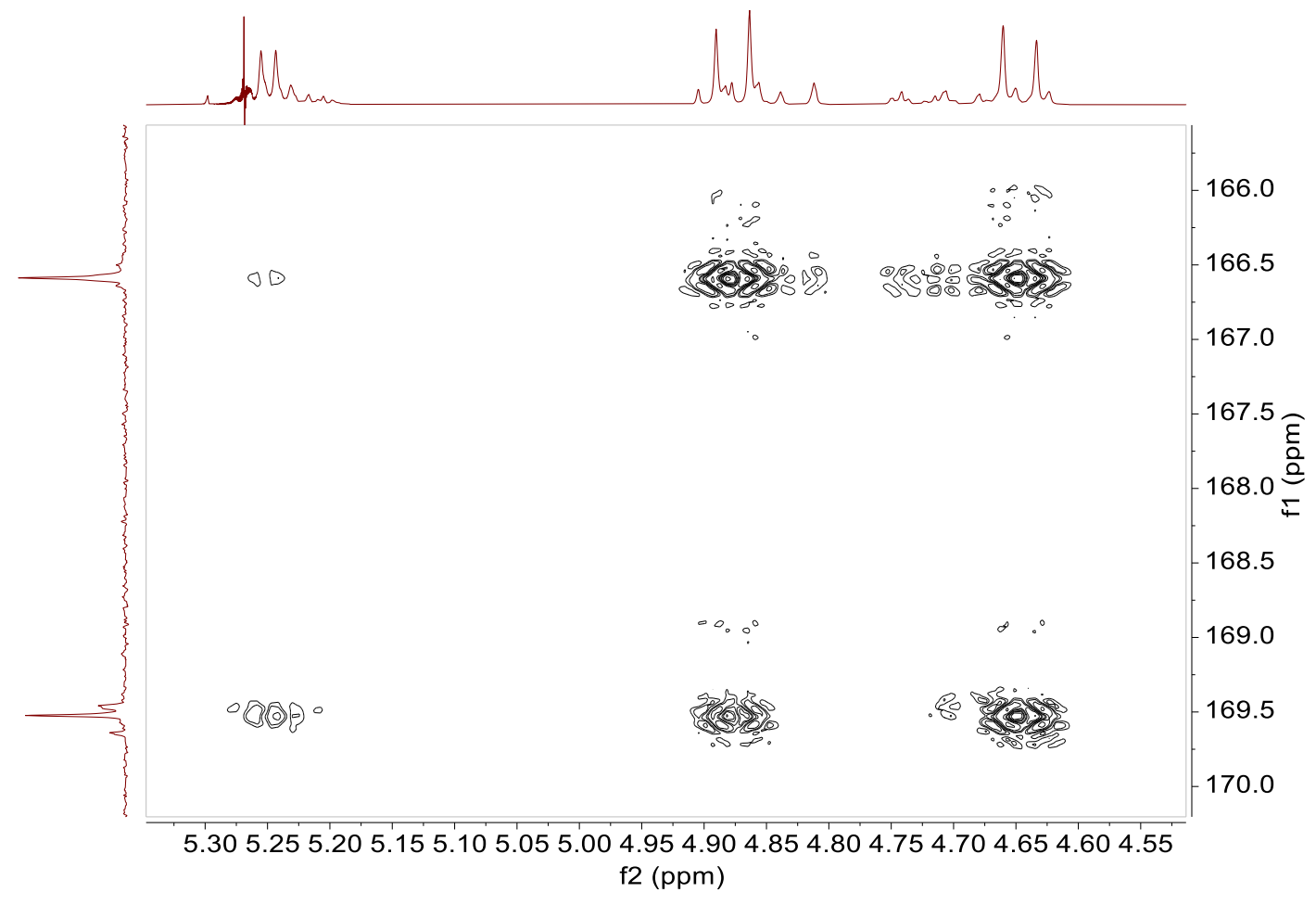

Figure S28. Methine and methylene regions (expanded) from band-selective HMBC $\left(600 / 150 \mathrm{MHz}, \mathrm{CDCl}_{3}\right)$ of alt-PLGA (regioselectivity $\left.=85 \%\right)$.

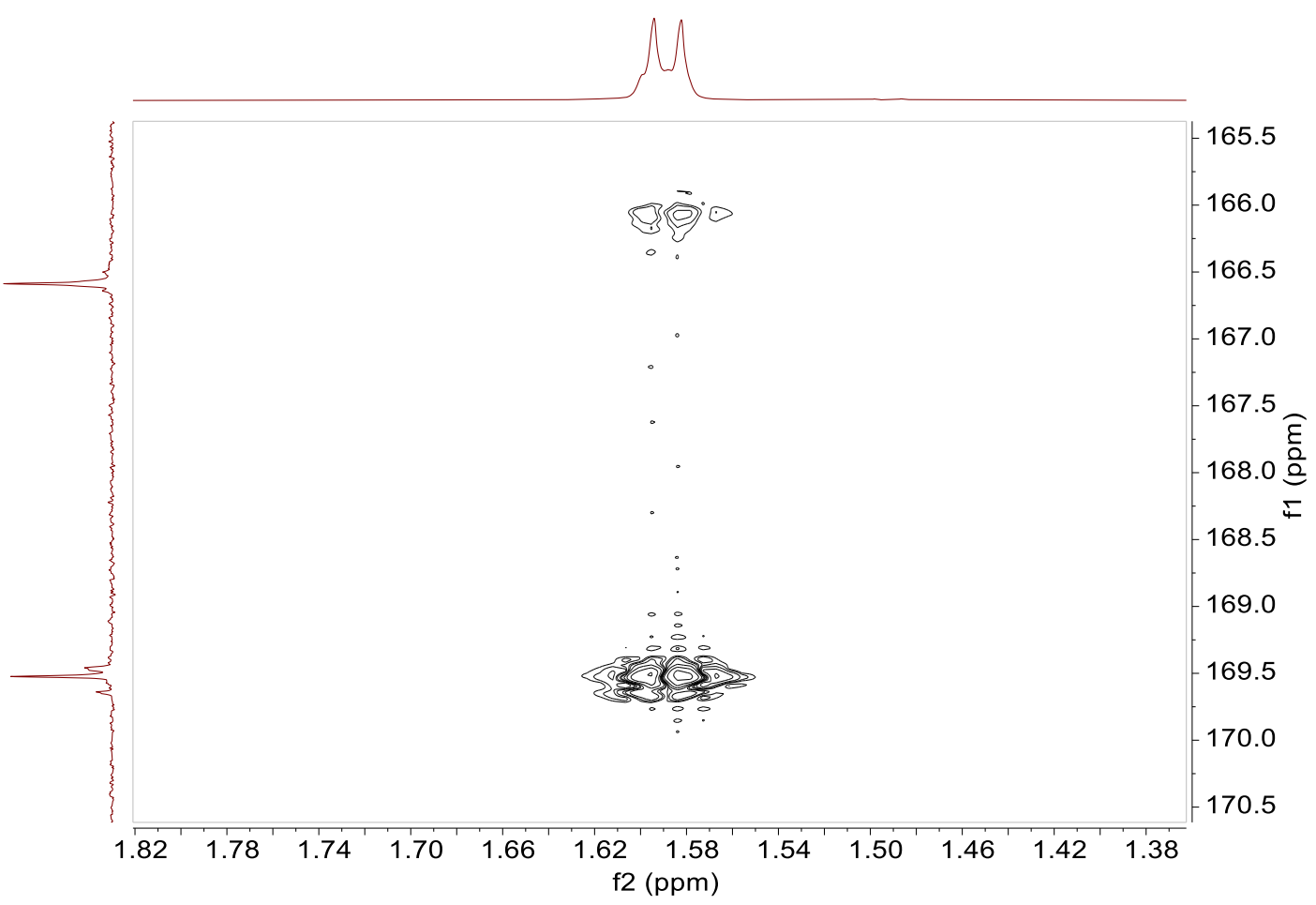

S32 
Figure S29. Methyl region (expanded) from band-selective $\mathrm{HMBC}\left(600 / 150 \mathrm{MHz}, \mathrm{CDCl}_{3}\right)$ of alt-PLGA (regioselectivity $=85 \%$ ).

Table S2. Methylene region NMR peak assignments of alt-PLGA (regioselectivity = $85 \%$ ).

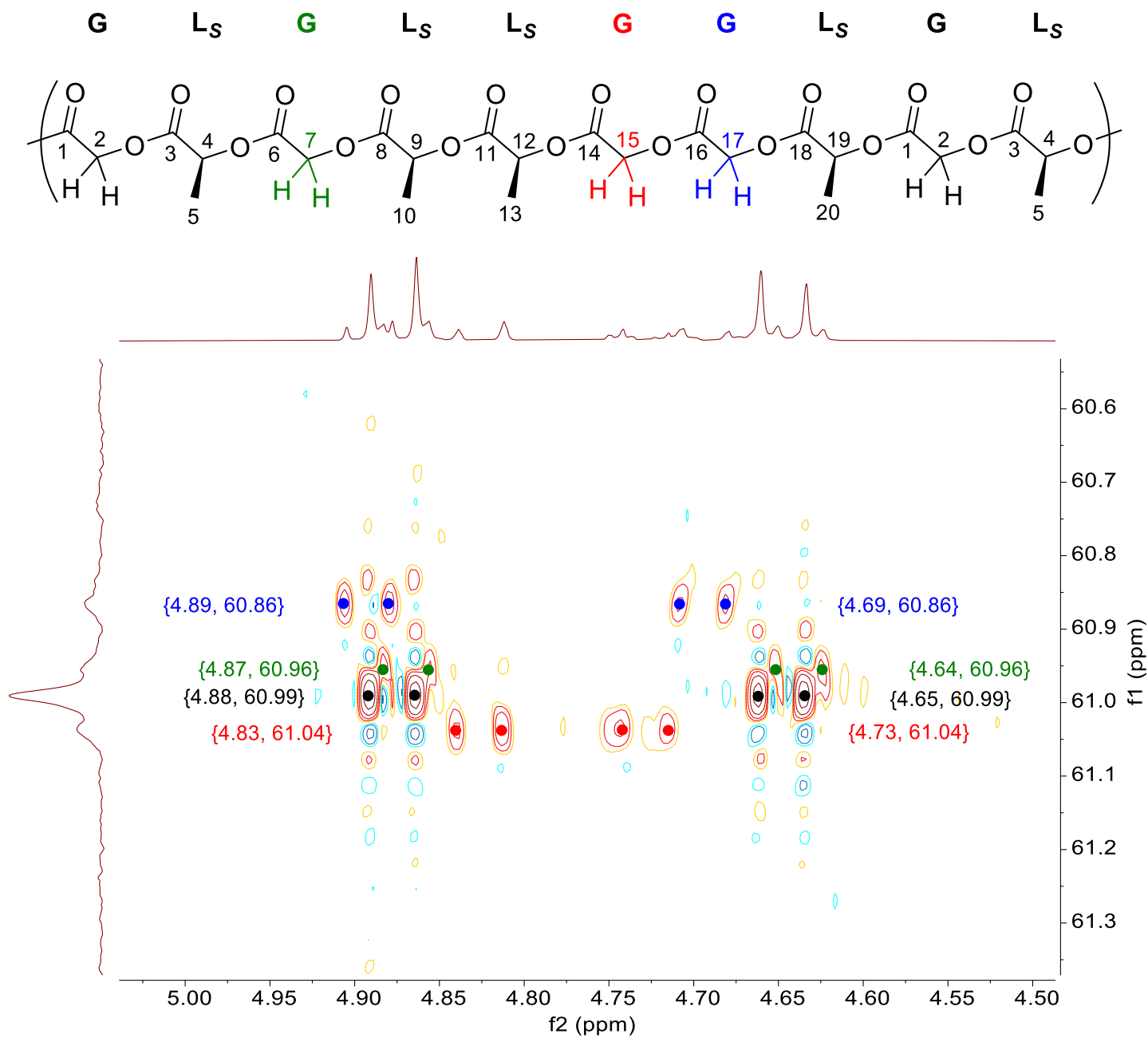

$\begin{array}{cccc}\text { position } & \delta_{\mathrm{C}}(\mathrm{ppm}) & \delta_{\mathrm{H}}(\mathrm{ppm}) & \text { Relevant HMBC correlations } \\ 1 & 166.59 & & 1,3 \\ 2 & 60.99 & 4.65,4.88 & \\ 3 & 169.52 & & 3,5,6 \\ 4 & 69.31 & 5.25 & 3,4 \\ 5 & 16.90 & 1.59 & 6,8 \\ 7 & 60.96 & 4.64,4.87 & 14,16 \text { (glycolic carbonyl only) } \\ 15 & 61.04 & 4.73,4.83 & 16,18 \\ 17 & 60.86 & 4.69,4.89 & \end{array}$




\section{References}

(1) Washington, M. A.; Swiner, D. J.; Bell, K. R.; Fedorchak, M. V.; Little, S. R.; Meyer, T. Y. The impact of monomer sequence and stereochemistry on the swelling and erosion of biodegradable poly(lactic-co-glycolic acid) matrices. Biomaterials 2017, 117, 66-76.

(2) Ornelas, A.; Korczynska, M.; Ragumani, S.; Kumaran, D.; Narindoshvili, T.; Shoichet, B. K.; Swaminathan, S.; Raushel, F. M. Functional Annotation and Three-Dimensional Structure of an Incorrectly Annotated Dihydroorotase from $\operatorname{cog} 3964$ in the Amidohydrolase Superfamily. Biochemistry 2013, 52, 228-238.

(3) Lozhkin, B. A.; Shlyakhtin, A. V.; Bagrov, V. V.; Ivchenko, P. V.; Nifant'ev, I. E. Effective stereoselective approach to substituted 1,4-dioxane-2,5-diones as prospective substrates for ring-opening polymerization. Mendeleev Commun. 2018, 28, 61-63.

(4) Ovitt, T. M.; Coates, G. W. Stereoselective Ring-Opening Polymerization of mesoLactide: Synthesis of Syndiotactic Poly(lactic acid). J. Am. Chem. Soc. 1999, 121, 4072-4073.

(5) Colombo, F.; Benaglia, M.; Orlandi, S.; Usuelli, F. Asymmetric multicomponent copper catalyzed synthesis of chiral propargylamines. J. Mol. Catal. A: Chem. 2006, 260, $128-134$.

(6) Turova, N. Y.; Kozunov, V. A.; Yanovskii, A. I.; Bokii, N. G.; Struchkov, Y. T.; Tarnopol'skii, B. L. Physico-chemical and structural investigation of aluminium isopropoxide. J. Inorg. Nucl. Chem. 1979, 41, 5-11.

(7) D'Alterio, M. C.; De Rosa, C.; Talarico, G. Stereoselective Lactide Polymerization: the Challenge of Chiral Catalyst Recognition. ACS Catal. 2020, 10, 2221-2225. 